\title{
Significance of molecular classification of ependymomas: C11orf95-RELA fusion- negative supratentorial ependymomas are a heterogeneous group of tumors
}

Kohei Fukuoka ${ }^{1,2}$, Yonehiro Kanemura ${ }^{3,4}$, Tomoko Shofuda ${ }^{3}$, Shintaro Fukushima ${ }^{1}$, Satoshi Yamashita ${ }^{5}$, Daichi Narushima ${ }^{6}$, Mamoru Kato ${ }^{6}$, Mai Honda-Kitahara ${ }^{1}$, Hitoshi Ichikawa7 ${ }^{7}$ Takashi Kohno ${ }^{8}$, Atsushi Sasaki ${ }^{9}$, Junko Hirato $^{10}$, Takanori Hirose ${ }^{11}$, Takashi Komori ${ }^{12}$, Kaishi Satomi ${ }^{1,13}$, Akihiko Yoshida ${ }^{13}$, Kai Yamasaki ${ }^{1,14}$, Yoshiko Nakano 1,14, Ai Takada3 ${ }^{3}$, Taishi Nakamura 1,15, Hirokazu Takami 1,16, Yuko Matsushita,17, Tomonari Suzuki ${ }^{2}$, Hideo Nakamura ${ }^{18}$, Keishi Makino ${ }^{19}$, Yukihiko Sonoda ${ }^{20,21}$, Ryuta Saito ${ }^{21}$, Teiji Tominaga ${ }^{21}$, Yasuhiro Matsusaka ${ }^{22}$, Keiichi Kobayashi ${ }^{23}$, Motoo Nagane ${ }^{23}$, Takuya Furuta ${ }^{24,25}$, Mitsutoshi Nakada ${ }^{24}$, Yoshitaka Narita ${ }^{17}$, Yuichi Hirose ${ }^{26}$, Shigeo Ohba ${ }^{26}$, Akira Wada ${ }^{27}$, Katsuyoshi Shimizu ${ }^{27}$, Kazuhiko Kurozumi ${ }^{28}$, Isao Date ${ }^{28}$, Junya Fukai ${ }^{29}$, Yousuke Miyairi ${ }^{30}$, Naoki Kagawa ${ }^{31}$, Atsufumi Kawamura ${ }^{32}$, Makiko Yoshida ${ }^{33}$, Namiko Nishida ${ }^{34}$, Takafumi Wataya ${ }^{35}$, Masayoshi Yamaoka ${ }^{36}$, Naohiro Tsuyuguchi ${ }^{31}$, Takehiro Uda ${ }^{31}$, Mayu Takahashi ${ }^{37}$, Yoshiteru Nakano ${ }^{37}$, Takuya Akai ${ }^{38,39}$, Shuichi Izumoto ${ }^{40}$, Masahiro Nonaka ${ }^{41}$, Kazuhisa Yoshifuji ${ }^{42}$, Yoshinori Kodama ${ }^{43,44}$, Masayuki Mano ${ }^{44}$, Tatsuya Ozawa', Vijay Ramaswamy ${ }^{45}$, Michael D. Taylor ${ }^{45,46}$, Toshikazu Ushijima ${ }^{5}$, Soichiro Shibui ${ }^{47}$, Mami Yamasaki ${ }^{48}$, Hajime Arai ${ }^{49}$, Hiroaki Sakamoto ${ }^{22}$, Ryo Nishikawa ${ }^{2}$, Koichi Ichimura ${ }^{1 *}$, on behalf of the Japan Pediatric Molecular Neuro-Oncology Group (JPMNG)

\begin{abstract}
Extensive molecular analyses of ependymal tumors have revealed that supratentorial and posterior fossa ependymomas have distinct molecular profiles and are likely to be different diseases. The presence of C110rf95-RELA fusion genes in a subset of supratentorial ependymomas (ST-EPN) indicated the existence of molecular subgroups. However, the pathogenesis of RELA fusion-negative ependymomas remains elusive. To investigate the molecular pathogenesis of these tumors and validate the molecular classification of ependymal tumors, we conducted thorough molecular analyses of 113 locally diagnosed ependymal tumors from 107 patients in the Japan Pediatric Molecular Neuro-Oncology Group. All tumors were histopathologically reviewed and 12 tumors were re-classified as non-ependymomas. A combination of RT-PCR, FISH, and RNA sequencing identified RELA fusion in 19 of 29 histologically verified ST-EPN cases, whereas another case was diagnosed as ependymoma RELA fusion-positive via the methylation classifier (68.9\%). Among the 9 RELA fusion-negative ST-EPN cases, either the YAP1 fusion, BCOR tandem duplication, EP300-BCORL1 fusion, or FOXO1-STK24 fusion was detected in single cases. Methylation classification did not identify a consistent molecular class within this group. Genome-wide methylation profiling successfully sub-classified posterior fossa ependymoma (PF-EPN) into PF-EPN-A (PFA) and PF-EPN-B (PFB). A multivariate analysis using Cox regression (Continued on next page)
\end{abstract}

\footnotetext{
*Correspondence: kichimur@ncc.go.jp

'Division of Brain Tumor Translational Research, National Cancer Center

Research Institute, 5-1-1 Tsukiji, Chuo-ku, Tokyo 104-0045, Japan

Full list of author information is available at the end of the article
}

(c) The Author(s). 2018 Open Access This article is distributed under the terms of the Creative Commons Attribution 4.0 International License (http://creativecommons.org/licenses/by/4.0/), which permits unrestricted use, distribution, and reproduction in any medium, provided you give appropriate credit to the original author(s) and the source, provide a link to the Creative Commons license, and indicate if changes were made. The Creative Commons Public Domain Dedication waiver (http://creativecommons.org/publicdomain/zero/1.0/) applies to the data made available in this article, unless otherwise stated. 


\begin{abstract}
(Continued from previous page)
confirmed that PFA was the sole molecular marker which was independently associated with patient survival. A clinically applicable pyrosequencing assay was developed to determine the PFB subgroup with 100\% specificity using the methylation status of 3 genes, CRIP1, DRD4 and LBX2. Our results emphasized the significance of molecular classification in the diagnosis of ependymomas. RELA fusion-negative ST-EPN appear to be a heterogeneous group of tumors that do not fall into any of the existing molecular subgroups and are unlikely to form a single category.
\end{abstract}

Keywords: Ependymal tumors, Fusion gene, Gene rearrangement, Molecular classification

\section{Introduction}

Ependymal tumors are classified into four histopathological subtypes including subependymoma (grade I), myxopapillary ependymoma (grade I), ependymoma (grade II), ependymoma, RELA fusion-positive (grade II or III), and anaplastic ependymoma (grade III) according to the World Health Organization (WHO) Classification of Tumours of the Central Nervous System [8]. Each of the latter two, which are clinically malignant, is defined as "A circumscribed glioma composed of uniform small cells with round nuclei in a fibrillary matrix and characterized by perivascular anucleate zones (pseudorosettes) with ependymal rosettes also found in about one quarter of cases (ependymoma), a high nuclear-to-cytoplasmic ratio, and a high mitotic count (anaplastic ependymoma)" [8]. Ependymal tumors, which may arise from any part of the neuroaxis, are identified as supratentorial (ST), posterior fossa (PF) or spinal (SP) ependymomas (EPNs). Malignancy grading for EPN and anaplastic EPN is often inconsistent, and the clinical significance of EPN pathological grading is controversial [20, 25, 28, 32]. Regardless of location, standard treatment for these tumors involves maximal safe surgical resection followed by local radiation therapy [29]. Incomplete resection or recurrence predicts a dismal prognosis. At present, there are no reports of chemotherapeutic agents with proven efficacy against these tumors [11, 35]. Therefore, further clarification of molecular mechanisms underlying the genesis of EPN, as well as development of new treatments for these tumors may be essential.

A series of extensive molecular analyses has demonstrated that supratentorial and posterior fossa EPNs may have distinct molecular profiles and are most likely separate diseases $[19,25,27,29,37]$. Recently, a consensus scheme for the molecular classification of EPNs based on these studies has been proposed [25]. ST-EPNs were segregated into two molecular subgroups denoted as ST-EPN-RELA and ST-EPN-YAP1. ST-EPN-RELA tumors, which are characterized by the presence of various types of C11orf95-RELA fusion genes, account for approximately 70\% of ST-EPNs [27]. Some C11orf95-RELA fusion genes have been experimentally demonstrated as oncogenic. ST-EPN-YAP1 subgroup is characterized by the YAP1. ST-EPN-YAP1 fusion gene, which is much less common than ST-EPN-RELA. The oncogenic potential of most YAP1 fusions remain to be determined. However, fusion genes are often intimately implicated in tumorigenesis. Therefore, fusion genes that are highly specific to ST-EPN are likely to be promising therapeutic targets for these particular tumors. However, diagnosis and clinical significance of the C11orf95-RELAor YAP1-fusion negative ST-EPNs remains controversial. Whether these tumors harbor an unidentified driver event or belong to an entity that is entirely different from EPN, needs to be determined. Thus, a detailed investigation of the molecular profiles of these tumors was felt to be imperative.

According to the methylation pattern, PF-EPNs are segregated into two main molecular subgroups termed PF-EPN-A (PFA) and PF-EPN-B (PFB) [19, 25]. PFA subgroup tumors are characterized by an increased DNA methylation pattern in the CpG islands, which is different from that seen in PFB ependymomas. PFA patients are mostly infants or young children associated with a poor prognosis whereas PFB patients are older with better prognoses $[19,25]$. No recurrent driver mutation, identifiable as a therapeutic target or diagnostic marker, has been found in either subgroup. Because the presence of biologically distinct subgroups within PF-EPN has significant clinical implications, validation of these sub groups as well as development of robust diagnostic tools for these groups are deemed essential.

For the purpose of molecular and clinical characterization of ependymal tumors and identification of therapeutic targets, we performed molecular analyses on a considerable series of ependymal tumors collected via the Japan Pediatric Molecular Neuro-oncology Group (JPMNG). These cases were examined using detailed clinical information and centrally reviewed histopathology. We confirmed that RELA fusion is a highly specific diagnostic marker for ST-EPN, and that methylationbased classification of PF-EPN is robust and may serve as an independent prognostic marker. We found that a considerable proportion of histopathologically diagnosed ST-EPN does not contain the RELA fusion, and that the molecular pathogenesis of these tumors may be complex. 


\section{Materials \& methods}

\section{Tumor material}

A total of 113 locally diagnosed ependymal tumors collected from 107 patients through JPMNG were examined in this study (Table 1). Among these, 38 were supratentorial, 63 were posterior fossa and 12 were spinal tumors. In all cases, a consensus diagnosis was made by three neuropathologists (A.S., T.H., and J.H.) following an extensive microscopic review of slides stained with hematoxylin, eosin and other immunohistochemistry procedures. In addition, 69 PF-EPN samples from the Hospital for Sick Children,
Toronto, Canada, were included for validation of a pyrosequencing assay developed for molecular classification of PF-EPN (see below). This study was approved by the ethics committees of the National Cancer Center as well as the respective local institutional review boards.

\section{DNA/RNA extraction, CDNA synthesis, and bisulfite modification of DNA}

DNA and RNA were extracted from the tumor samples, using a DNeasy Blood \& Tissue kit (Qiagen, Tokyo, Japan) and Qiagen miRNeasy Mini Kit, respectively. First

Table 1 Patient characteristics

\begin{tabular}{|c|c|c|}
\hline Total number of enrolled patients & & 107 \\
\hline Male:female ratio & & 55: 51 (Unknown, 1) \\
\hline Observation period (median, range) & & 49 months (0-219) \\
\hline Age (median, range) & 10 years, $(0-76$ years $)$ & \\
\hline & $<3$ & 22 \\
\hline & $3-18$ & 42 \\
\hline & $18<$ & 42 \\
\hline & Unknown & 1 \\
\hline Extent of resection of the primary tumors & Total resection & 51 \\
\hline & Partial resection/biopsy & 47 \\
\hline & Unknown & 9 \\
\hline Adjuvant therapy for the primary tumors & Radiation therapy (RTx) & 32 \\
\hline & Chemotherapy (CTx) & 13 \\
\hline & $R T x+C T x$ & 22 \\
\hline & No adjuvant therapy & 29 \\
\hline & No data & 11 \\
\hline Total number of enrolled samples & & 113 \\
\hline Tumor locations & Supratentorial & 38 \\
\hline & Posterior fossa & 63 \\
\hline & Spine & 12 \\
\hline Time of surgery for the samples & Primary & 91 \\
\hline & Recurrent & 18 \\
\hline & Unknown & 4 \\
\hline Pathological diagnosis (Institutional diagnosis) & Grade 1 & 2 \\
\hline & Grade 2 & 46 \\
\hline & Grade 3 & 60 \\
\hline & No data of grading & 5 \\
\hline Pathological diagnosis (Central diagnosis) & Grade 1 & 1 \\
\hline & Grade 2 & 33 \\
\hline & Grade 3 & 67 \\
\hline & Other diagnoses & 12 \\
\hline Molecular status & RELA fusion positive & 20 \\
\hline & YAP1 fusion positive & 1 \\
\hline & PFA & 45 \\
\hline & PFB & 15 \\
\hline
\end{tabular}


strand cDNA was synthesized using a SuperScript III Reverse Transcriptase kit (Life Technologies, Tokyo, Japan), according to the manufacturer's instructions. Bisulfite modification of DNA was performed using an EZ Methylation DNA Kit (Zymo Research, CA, USA).

\section{Genome-wide DNA methylation analysis}

Genome-wide DNA methylation analysis was performed using an Infinium HumanMethylation450 BeadChip array (Illumina, San Diego, CA, USA, hereafter 450 array) which includes 485,512 CpG sites for analysis, as described previously $[11,38]$. For the methylation array, $500 \mathrm{ng}$ of DNA extracted from fresh frozen specimens and $100 \mathrm{ng}$ DNA from formalin-fixed paraffin-embedded (FFPE) specimens, repaired using an Infinium HD FFPE Restore Kit (Illumina, San Diego, CA, USA), was used. We removed 11,551 probes mapped on sex chromosomes and employed the remaining 473,961 probes for analysis. The methylation level of each CpG site was expressed using beta-values, ranging from 0 (unmethylated) to 1 (fully methylated). A total of 3086 probes showing a high standard deviation ( $\mathrm{SD}>0.25)$ on $\mathrm{CpG}$ islands, were selected for PF-EPN classification. Unsupervised hierarchical clustering was performed using $\mathrm{R}$ software (version 3.0.1), as described previously [15]. Methylation data of 48 EPNs (GSE42752) and 6 normal cerebellums (GSE44684) [17, 19, 33] were obtained from the Gene Expression Omnibus database (http://www.ncbi.nlm.nih.gov/geo/) for comparison with our data. The methylation profiling classifier developed by the German Cancer Research Center (DKFZ)/University Hospital Heidelberg/German Consortium for Translational Cancer Research (DKTK) (the DKFZ classifier, molecularneuropathology.org) was used via their website to assign subtype scores for each tumor [4].

\section{Copy number analysis}

Copy number alterations were evaluated using signal data from the methylation array. Following an evaluation of methylated and unmethylated signals in the six normal cerebellum samples, probes showing high variability were excluded from the analysis [17]. Probes outside the 0.05 and 0.95 quantiles of median summed values, as well as probes over the 0.8 quantile of the median absolute deviation were excluded. Sample to median Log2-ratios of control samples at each probe were calculated and normalized against the median log2-ratio. Copy number data were obtained using the DKFZ classifier.

\section{PCR, RT-PCR, and sanger sequencing}

PCR and RT-PCR were performed using an AmpliTaq Gold 360 kit (Applied Biosystems, Foster City, CA, USA). Following purification with ExoSAP-IT (Affymetrix USB, Cleveland, OH, USA), Sanger sequencing was performed using a BigDye Terminator v1.1 Cycle Sequencing
Kit (Applied Biosystems, Foster City, CA, USA) for screening TERT C228T and C250T mutations, and a BigDye Terminator v3.1 Cycle Sequencing Kit (Applied Biosystems, Foster City, CA, USA) for screening other genes on an auto sequencer (3130xl Genetic Analyzer, Applied Biosystems, Foster City, CA) in the sequencing analysis. The primer sequences are shown (Additional file 1 Table S1).

\section{Fluorescence in situ hybridization (FISH)}

Break-apart FISH was used to detect RELA or YAP1 fusion. FISH was performed on 4-5 $\mu \mathrm{m}$ sections of each FFPE specimen. FISH probes were derived from the following BAC clones: for RELA fusion detection, RP11-472D15 and RP11-58D3 probes were labeled with spectrum orange, whereas RP11-692F22 and CTD-2121 M3 probes were labeled with spectrum green; for YAP1 fusion detection, RP11-732A21 and RP11-640G3 were labeled with spectrum orange and RP11-1082I3 and RP11-315O6 with spectrum green. Briefly, BAC DNA from an overnight culture of the corresponding BAC clones was purified using a GenElute Plasmid Miniprep Kit (Sigma-Aldrich, Tokyo, Japan), amplified using a Templiphi Amplification Kit (GE Healthcare, Tokyo, Japan) and labeled using a Nick Translation Kit (Abbott Molecular, Abbott Park, IL) with appropriate dye-coupled dUTP, as per manufacturer's instructions. Fluorescence in situ hybridization was performed as previously described [22]. Scoring of FISH results was performed using a BZ-9000 fluorescence microscope (Keyence, Osaka, Japan) with appropriate filters at 1000x magnification. A tissue microarray containing a tumor with a known YAP1 fusion, kindly provided by Dr. David Ellison from St. Jude Children's Research Hospital, was used as a positive control.

\section{Expression analysis}

mRNA expression levels were evaluated via real-time quantitative PCR (qPCR) using the LightCycler 480 SYBR Green I Master and the SYBR Green I (483-533 nm) detection format on a CFX96 (Bio-Rad Laboratories, Inc., Hercules, CA, USA), according to the manufacturer's instructions. The primer pairs used to perform qPCR were as follows: TERT - forward primer (P570) located in exon 6 and reverse primer (P571) located in exon 7; and EZH2 - forward primer (P563) located in exon 2 and reverse primer (P564) located in exon 3. The expression level of $H 6 P D$, determined via the primer pair, (P114) and (P115), was used as an internal reference for normalization. PCR conditions were as follows; $95{ }^{\circ} \mathrm{C}$ for $5 \mathrm{~min}, 45$ cycles of $10 \mathrm{~s}$ at $95{ }^{\circ} \mathrm{C}$ each, $55{ }^{\circ} \mathrm{C}$ for $10 \mathrm{~s}$ and $72{ }^{\circ} \mathrm{C}$ for $10 \mathrm{~s}$. A standard curve was generated using serially diluted cloned PCR products of both the internal reference and target genes. Expression was measured relative to the human total brain RNA (Clontech Laboratories, Mountain View, 
CA, USA). Primer sequences are described (Additional file 1 Table S1).

\section{Mutation analysis by pyrosequencing}

Hot spot mutations of IDH1 (R132), IDH2 (R172), BRAF (V600E), H3F3A (K27 M, G34R), FGFR1 (N546, N656) and $H I S T 1 H 3 B(\mathrm{~K} 27 \mathrm{M})$ were evaluated via pyrosequencing. Methylation analysis of TERT promoter regions and/or 3 upstream transcription starting sites (UTSSs, R1, R2 and R3) were performed as reported previously [3, 5]. Primer sequences, analyzed sequences and the dispensation order are shown (Additional file 1 Table S1). Pyrosequencing was performed using the AQ assay of PyroMark Q96 (version 2.5.7) on a PyroMark ID pyrosequencer (Qiagen, Tokyo, Japan), according to the manufacturer's instructions.

\section{PF-EPN subgroup prediction by pyrosequencing}

A set of pyrosequencing assays was developed in order to sub-classify PF-EPN into PFA or PFB effectively. At first, 10 PFA and 10 PFB cases were investigated as a discovery set (Results and Additional file 2 Tables S2 and Additional file 3 Table S3). Highly methylated probes (mean beta-value $\geq 0.5$ ) in PFA cases and hypomethylated probes (mean beta-value $\leq 0.2$ ) in PFB cases, were selected from our discovery set and archival data set $(n=48)$ with an Infinium HumanMethylation450 BeadChip array [19]. Out of the 414,634 probes used, 13 probes covering 3 genes, CRIP1, $L B X 2$, and $D R D 4$, located in the autosomes were selectively identified, (Additional file 2 Table S2). Next, a set of pyrosequencing assays was designed to examine the methylation status of $\mathrm{CpG}$ sites, as well as their flanking CpG sites, targeted by the probes cg04411625 (CRIP1), cg03270710 (LBX2), cg20931042 and cg06825142 (DRD4). Primers and dispensation orders are listed (Additional file 1 Table S1). Methylation levels were measured using the $\mathrm{CpG}$ assay of PyroMark Q96 (see above). Mean methylation levels of all CpG sites included in each assay were used to represent the methylation status of each gene. Methylation levels at these CpG sites measured via pyrosequencing showed good concordance with those of the $450 \mathrm{~K}$ array (data not shown). The dataset containing 54 cases from the JPMNG cohort and 69 cases from the SickKids cohort was used in the training and validation processes for the prediction rule design, (Additional file 4 Figure S5a). The original dataset of JPMNG and SickKids was preprocessed via random sampling and divided on a 1:2 basis into a training dataset containing 41 cases (PFA: 30, PFB: 11) and a validation dataset containing 82 cases (PFA: 60, PFB: 22), while maintaining the PFA:PFB ratio. Statistical analysis and determination of the cutoff are described in Results.

\section{Whole transcriptome sequencing}

The TruSeq RNA Sample Prep Kit (Illumina, CA, USA) was used to prepare RNA sequencing libraries from total RNA. Samples with an RNA integrity number of 6 or less were prepared using TruSeq Stranded Total RNA with Ribo-Zero Gold LT Sample Prep Kit (Illumina, CA, USA). The resultant libraries were subjected to pairedend sequencing of 75-bp reads on a HiSeq 2000 (Illumina, CA, USA). Fusion transcripts were detected using the TopHat-Fusion algorithm [14] (Additional file 5 Table S4). For expression analysis, we established "virtual" Agilent $8 \times 60 \mathrm{~K}$ array data from RNA sequencing data by counting the number of inserts expected to hybridize on probe positions of the array (VA). The data was normalized by the median number of inserts.

\section{Immunohistochemical analysis of $\mathrm{H} 3 \mathrm{~K} 27 \mathrm{me} 3$}

Of the 60 PF-EPNs that were subjected to consensus diagnosis and molecular subclassification into PFA or PFB, 44 cases were available for evaluation using immunohistochemistry. Four-micrometer-thick sections cut from blocks representing each tumor were deparaffinized. The preparations were autoclaved in citrate buffer $(\mathrm{pH} 6.0)$, and endogenous peroxidase activity was blocked with $3 \%$ hydrogen peroxide. The primary antibody used was the anti-H3K27me3 rabbit monoclonal antibody (C36B11, dilution 1:200; Cell Signaling Technology, Danvers, MA, USA). Slides were incubated for $1 \mathrm{~h}$ at room temperature with the primary antibody, and subsequently labeled by using the EnVision system (Dako, Glostrup, Denmark). Diaminobenzidine was used as the chromogen, and hematoxylin as the counterstain. The entire area of the stained slides was visually inspected, and the percentage of cells that lacked staining was assessed semi-quantitatively. Cases were categorized as showing intact expression when over $80 \%$ of tumor cells were intact for H3K27me3, or as showing reduced expression when 0$80 \%$ of tumor cells were labeled as intact [26]. Staining was deemed evaluable only if endothelial cells in the tumor tissue showed intact reactivity. Staining intensity was not used as a parameter for evaluation.

\section{Statistical analysis}

Comparison between subgroups was performed using the Student's $t$-test, Pearson's chi-square test, Fisher's exact test and the Wilcoxon rank-sum test. Overall survival (OS) was defined as the probability of survival, with death as the only event. Progression-free survival (PFS) was defined as the probability of being alive without a risk of progression or relapse. Survival curves were plotted using the Kaplan-Meier method. The log-rank test and Cox proportional hazards model were used to detect differences in survival between different groups of patients. Two-sided tests were used for all analyses, and 
the significance level was set at $P<0.05$. JMP 10 (SAS Institute Inc., Cary, NC, USA) was used for all analyses.

\section{Results}

Central pathology review

A total of 113 locally diagnosed ependymomas (38 supratentorial, 63 posterior fossa and 12 spinal) analyzed in this study were subjected to a central review of histopathology (Table 1). Following this review, 1 myxopapillary EPN (grade I), 33 EPNs (grade II) and 67 anaplastic EPNs (grade III) were identified. Nine supratentorial and 3 posterior fossa tumors were re-classified as non-ependymal tumors. As a result, 29 supratentorial, 60 posterior fossa tumors (not including 3 re-reclassified posterior fossa tumors) and 12 spinal tumors were subjected to molecular analysis. Detailed results of histopathology related analyses will be published elsewhere (Sasaki, submitted).

\section{C11orf95-RELA fusion negative ST-EPNs are highly heterogeneous}

It has been proposed that ST-EPNs may be divided into three molecular subgroups; ST-EPN-RELA (RELA fusionpositive), ST-EPN-YAP1 (YAP1 fusion-positive) and ST-SE (subependymoma) [25, 27]. To validate the above molecular classification, we sought to identify fusions using a combination of RT-PCR, FISH, and/or RNA-sequencing analysis in ST-tumors $(n=38)$, including 9 tumors re-classified as non-ependymoma following a central review. C11orf95-RELA fusions were detected in 19 out of 29 ST-EPNs using RT-PCR and/or FISH (Fig. 1). All 19 RELA-fusion positive ST-EPNs were diagnosed as grade III after the central review. The RT-PCR used in this study detected 4 out of 7 C11orf95-RELA fusion transcripts reported so far [27]. A novel C11orf95-RELA fusion transcript, in which exon 2 of C11orf95 was fused to exon9 of RELA in-frame, was detected via RNA sequencing in an ST-EPN with a RELA fusion identified by FISH, but not by RT-PCR (EP15, Additional file 6 Figure S1a). C11orf95-RELA fusion was not detected in any of the 9 tumors re-classified following central review. One case (EP33) in which RELA fusion was not detected by either RT-PCR or FISH was classified to be RELA fusion-positive using DKFZ classifier results (see below). A copy number analysis using the $450 \mathrm{~K}$ array showed a copy number loss of upstream exon 2 of RELA, the most common break point of the fusion gene. Immunohistochemical staining of L1 cell adhesion molecule (L1CAM) showed strong positivity. These findings corroborated the result of the classifier (Additional file 7 Figure S6). EP33 was not subjected to RNA sequencing due to insufficient amount of RNA, and likely to have RELA fusion other than those examined by RT-PCR. As a result, out of 29 histologically verified ST-EPNs a total of 20 (68.9\%) were identified as RELA fusion-positive ependymomas.
YAP1 fusion was detected via FISH in only one grade III tumor (EP117, 1/29, 3.4\%). In this case, the fusion could not be studied further due to insufficient specimens. Thus, 8 histologically verified ST-EPN had neither RELA nor YAP1 fusions (Fig. 1). Chromothripsis, frequently found on chromosome 11 in ST-EPN is highly indicative of C11orf95-RELA fusion, and therefore considered to be one of its causal mechanisms [27]. Copy number analysis using $450 \mathrm{~K}$ array data indicated that of 20 ST-EPNs, 5 (25\%, data not shown) exhibited a highly unstable chromosome 11, which is highly suggestive of chromothripsis. No evidence of chromothripsis was observed in ST-EPNs, in the absence of RELA fusion or nonependymal tumors. There was no preferred age of onset, intracerebral location or tumor form (cystic or solid) in C11orf95-RELA-positive EPNs, as compared to RELAnegative tumors (Additional file 3 Table S3a).

Eight ST-EPNs negative for either C11orf95-RELA or YAP1-related fusion (4 grade II, and 4 grade III) were further investigated. Among those 8 cases, 3 demonstrated histological features of classic, Grade II ependymoma (EP97) or Grade III anaplastic ependymoma (EP3, EP32) whereas the remaining 5 exhibited evidence of ependymal differentiation as well as a variety of unusual features including astrocytic cells, tanycytic cells, vacuolated cells or microcysts (EP116, EP57, EP50, EP92, EP37, Additional file 8 Figure S7). RNA sequencing was performed in 5 tumors with sufficient amounts of RNA. We identified 2 novel in-frame fusion genes, EP300-BCORL1 (exon 31-exon 4) in one grade III tumor (EP3) and FOXO1STK24 (exon 1-exon 3) in one grade II tumor (EP57) (Fig. 1, Additional file 6 Figure S1 and Additional file 9 Figure S4). EP57 with FOXO1-STK24 fusion also exhibited copy number oscillations equivalent to chromothripsis in both chromosome 6 and 13, on which these genes are located (Additional file 6 Figure S1b). EP3 showed significantly higher expression of BCORL1 than RELA-fusion cases and the other non-RELA-fusion cases (Additional file 10 Figure S8). EP57 showed increased expression of both FOXO1 and STK24 compared to other RELA-fusion or non-RELA fusion ST-EPNs. The histology of EP3 and EP57 is presented in Additional file 8 Figure S7. In addition, a $B C O R$ tandem duplication recently reported in central nervous system-primitive neuroectodermal tumors (PNETs) was found in one case (EP116) with grade III ST-EPN [30] (data not shown). We further examined fusion-negative ST-EPNs by pyrosequencing for hot-spot mutations in IDH1, IDH2, TERT, BRAF V600E, H3F3A, HIST1H3B and FGFR1 [1, 2] (Additional file 1 Table S1). TERT promoter mutations $(\mathrm{C} 228 \mathrm{~T})$ were observed in one EPN grade II and one EPN grade III. The patients in these 2 cases were 45 and 56 years old. No mutations of the alterations examined were detected in the remaining cases. 


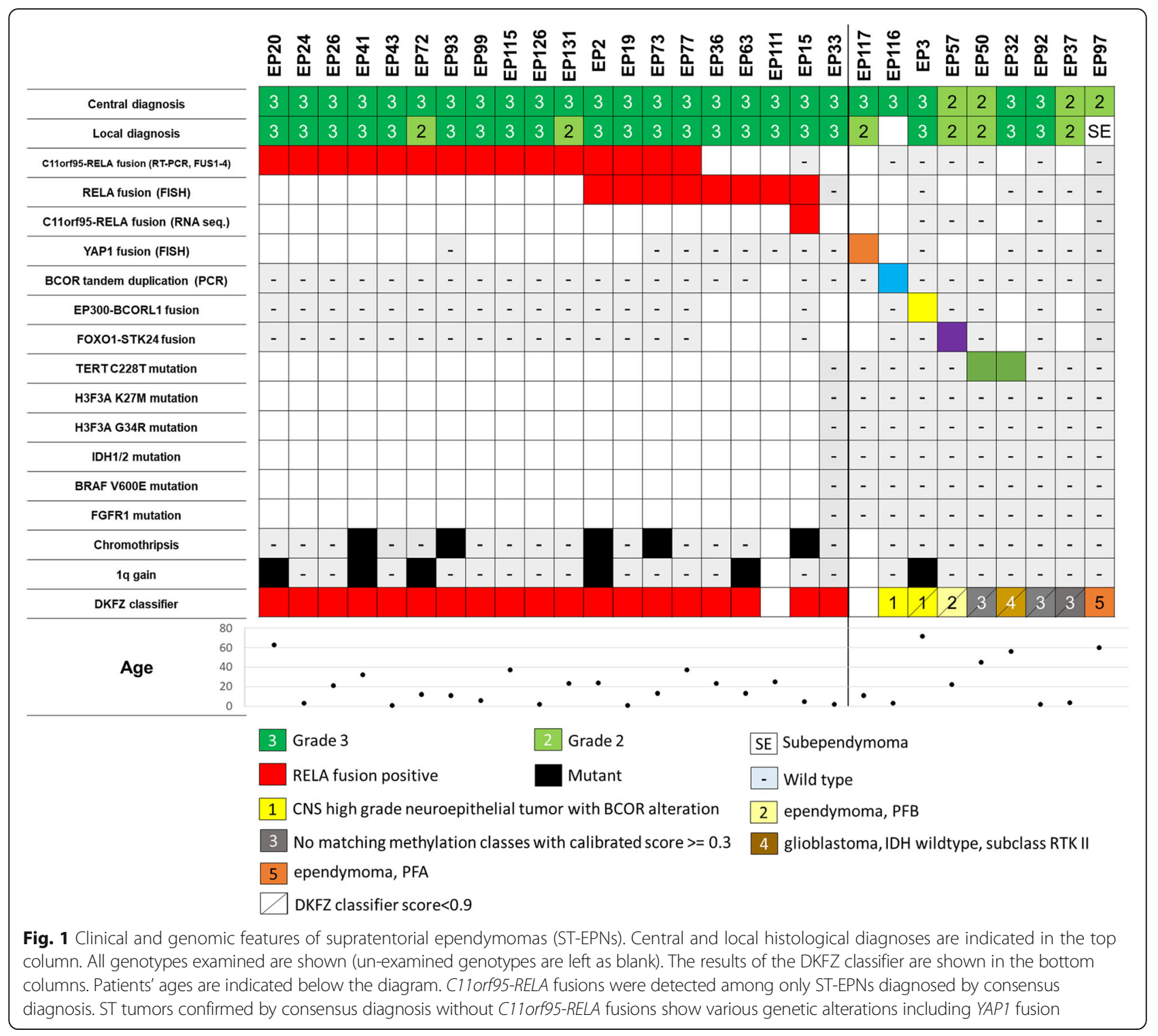

In order to further validate our molecular classification, the DKFZ classifier was applied to all cases via the DKFZ molecular neuropathology website (see Materials and Methods), except EP111 (RELA fusion) and EP117 (YAP1 fusion) which had insufficient material for an analysis to be performed. All RELA-positive ST-EPNs matched "methylation class ependymoma, RELA fusion" by the DKFZ classifier (score $>=0.90$ ); (Fig. 1 and Additional file 3 Table S3). The RELA-negative ST-EPNs displayed variability in regard to methylation classes as follows: 3 (EP50, EP92, EP37) with no matching methylation classes (calibrated score $>=0.3$; Fig. 1), 2 (EP116, EP3) with CNS high grade neuroepithelial tumors carrying the $B C O R$ alteration (BCOR altered tumor), 1 (EP97) with ependymoma PFA, 1(EP57) with ependymoma PFB and 1 (EP32) with glioblastoma $I D H$ wildtype subclass RTK II. Among the 3 cases with no matching methylation cases, 1 case carried a TERT promoter mutation and the other 2 cases exhibited no alterations via pyrosequencing of selected genes or RNA sequencing. Of the 2 tumors carrying $B C O R / B C O R L 1$ alterations, EP116 with a verified BCOR tandem duplication was classified as "CNS high grade neuroepithelial tumor with $B C O R$ alteration" (score = 0.99), whereas EP3 with the EP300-BCORL1 fusion with no match, was classified as "CNS high grade neuroepithelial tumor with $B C O R$ alteration" with a low score (0.44). EP57, with the FOXO1-STK24 fusion, was classified as ependymoma PFB with a low score (0.44). EP57 was a left occipital lobe tumor extending to the lateral ventricular wall, which was completely removed by surgery. EP97 was located in the right lateral ventricle, which was partially removed. Notably, of the ST-tumors re-classified as non- 
ependymomas by the central histology review, one tumor re-diagnosed as glioblastoma carried $H 3 F 3 A$ K27 M, and another re-diagnosed glioblastoma carried G34R (Additional file 3 Table S3). A BCOR tandem duplication was found in a high grade malignant tumor, not otherwise specified. These genotypes were matched with the DKFZ methylation classes with high scores.

\section{PF-EPNs are subclassified into PFA and PFB by methylation profile}

Although no recurrent genetic alterations have been identified in PF-EPNs, it was proposed that the PF-EPNs be segregated into two subgroups; PFA and PFB [19, 25]. To validate methylation-based classification, we investigated genome-wide methylation status of 60 PF-EPNs together with clinical information. Our $450 \mathrm{~K}$ array analysis segregated these PF-EPNs into two subgroups with distinct methylation profiles (Fig. 2). When our PF-EPNs were combined with a published PF-EPN dataset, the Toronto cohort (Material \& Methods), and analyzed, each of these two subgroups was clustered with published PFA or PFB, indicating that the $450 \mathrm{~K}$ array analysis was robust and accurately identified these two subgroups (data not shown). Our PFAs were generally matched with the DKFZ classifier results, although with lower scores in some cases, except 2 PFAs for which no match could be found. These 2 could not be even assigned as normal tissue. Posterior fossa PFB were mostly correctly diagnosed by the classifier as well, except for 3 tumors that were classified as a pituitary adenoma (EP96), ependymoma and a myxopapillary (EP86) and no matching class (EP40). When PF-EPN and SP-EPN were collectively analyzed, all but one spinal tumors were segregated with $\mathrm{PFB}$ (Additional file 11 Figure S2). Nine SP-EPN were classified

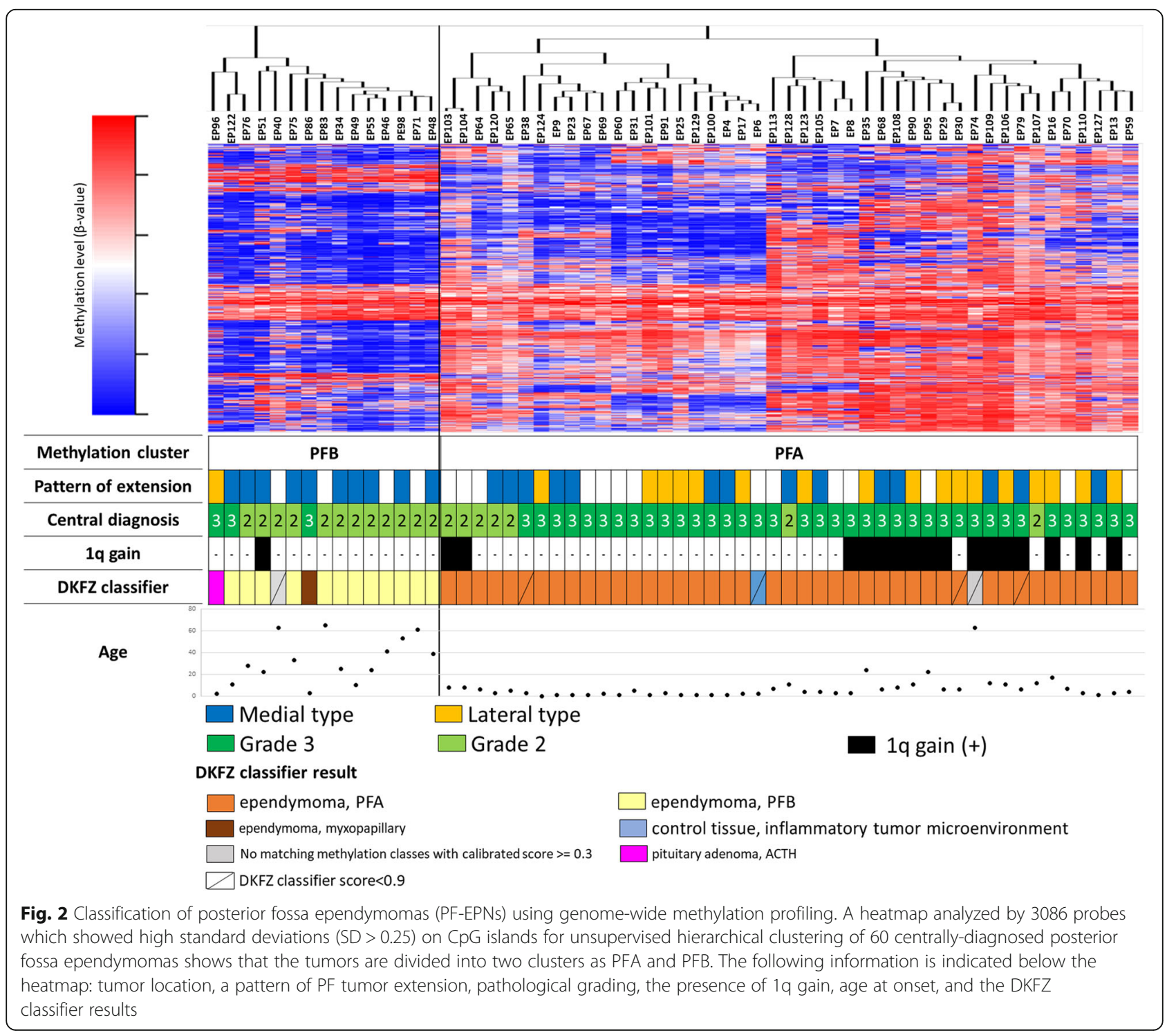


by the DKFZ classifier as spinal ependymomas, one as an adult plexus tumor, one as a pituitary adenoma and one with no matching class.

When molecular classification results were compared with clinical characteristics of intracranial PF-EPNs, excluding spinal EPN, PFA tumors $(n=45)$ occurred predominantly in younger patients $(p<0.001)$ and were laterally rather than medially located $(p=0.028)$ compared to PFB tumors (Additional file 3 Figure S3a, b). The great majority of PFAs were grade III while most PFBs were grade II $(p<0.001$, Additional file 3 Figure S3c). There was no difference in the resection rate between PFA and PFB (Additional file 3 Figure S3d). All 1q gain but one occurred in PFA (Fig. 2). PFA with 1q gain was observed in older patients $(p<0.001)$ and tended to develop spinal dissemination at onset $(p=0.09)$ as compared to PFA without 1q gain (Additional file 3 Figure S3e, g).

\section{PFA is the most significant prognostic factor in all EPNs}

We evaluated the prognosis prediction efficacy of molecular markers as well as clinical/pathological factors potentially associated with the survival of EPN patients. Only primary tumors were included in the survival analysis. High levels of EZH2 protein, TERT mRNA expression and hypermethylation of TERT upstream transcription starting sites (UTSSs) have previously been reported to be correlated with negative prognoses for EPN patients [5, 13, 16, 18, 21]. We investigated the status of these genes in the EPN cohort. Among the 4 molecular groups, ST-EPNs showed the highest EZH2 and TERT mRNA expression (Additional file 5 Figure S4a and S4b). Notably, TERT mRNA expression was 10 to 100 times higher in the C11orf95-RELA fusion-positive EPNs compared to all other EPN groups and even adult GBMs with the TERT promoter mutation (Additional file 5 Figure S4b). TERT UTSSs were highly methylated in the C11orf95-RELA fusion-positive ST-EPNs with high TERT mRNA expression (Additional file 5 Figure S4c).

A univariate analysis of all above data was performed to examine the efficacy of predicting prognosis of incomplete resection, WHO grade III, C11orf95-RELA fusion, PFA, 1q gain, high $E Z H 2$ expression, high TERT expression, and high TERT UTSS methylation status in all EPN patients whose clinical and molecular information was available (30 ST, $67 \mathrm{PF}+\mathrm{SP}$ ). High expression/methylation in EZH2/TERT was determined to be above the respective median value. The results showed that WHO grade III $(p=0.006)$, PFA $(p=0.0004)$ and 1q gain $(p=0.0003)$ were significantly associated with progression-free survival (PFS) (Table 2). WHO grade III $(p=0.001)$ and PFA $(p=0.0004)$ were significantly associated with shorter overall survival (OS). C11orf95-RELA fusion, high EZH2 expression, high TERT expression, or high TERT UTSS methylation were not associated with survival. Incomplete
Table 2 Univariate and Multivariate analysis of progression free survival (PFS) and Overall survival (OS) among all tumors

\begin{tabular}{|c|c|c|c|}
\hline Variable & $\begin{array}{l}\text { Hazard ratio } \\
(\mathrm{HR})\end{array}$ & $\begin{array}{l}95 \% \text { confidence } \\
\text { interval for HR }\end{array}$ & $p$-value \\
\hline \multicolumn{4}{|c|}{ Univariate analysis of PFS among all tumors } \\
\hline Incomplete resection & 1.66 & $0.30-1.17$ & 0.13 \\
\hline WHO grade3 & 2.91 & $1.34-7.26$ & 0.0057 \\
\hline C11orf95-RELA fusion & 0.59 & $0.29-1.50$ & 0.29 \\
\hline PFA & 3.30 & $1.69-6.72$ & 0.0004 \\
\hline 1q gain & 3.21 & $1.50-6.48$ & 0.0037 \\
\hline $\mathrm{EZH} 2$ high expression & 1.29 & $0.63-2.67$ & 0.49 \\
\hline TERT high expression & 1.18 & $0.58-2.42$ & 0.65 \\
\hline TERT UTSS high methylation & 1.42 & $0.72-2.96$ & 0.32 \\
\hline $\begin{array}{l}\text { Local radiation therapy }>= \\
50 G y\end{array}$ & 0.73 & $0.37-1.46$ & 0.37 \\
\hline Chemotherapy & 1.48 & $0.74-2.90$ & 0.26 \\
\hline \multicolumn{4}{|c|}{ Multivariate analysis of PFS among all tumors } \\
\hline WHO grade3 & 1.33 & $0.53-3.66$ & 0.55 \\
\hline PFA & 3.09 & $1.48-6.81$ & 0.0024 \\
\hline 1q gain & 2.79 & $1.25-5.99$ & 0.014 \\
\hline \multicolumn{4}{|c|}{ Univariate analysis of OS among all tumors } \\
\hline Incomplete resection & 2.22 & $0.17-1.09$ & 0.077 \\
\hline WHO grade3 & 6.31 & $1.84-39.6$ & 0.0017 \\
\hline C11orf95-RELA fusion & 0.46 & $0.07-1.61$ & 0.25 \\
\hline PFA & 5.47 & $2.16-16.7$ & 0.0002 \\
\hline 1q gain & 1.57 & $0.51-3.99$ & 0.40 \\
\hline EZH2 high expression & 1.21 & $0.46-3.21$ & 0.70 \\
\hline TERT high expression & 0.76 & $0.29-1.94$ & 0.57 \\
\hline TERT UTSS high methylation & 1.90 & $0.78-5.28$ & 0.16 \\
\hline $\begin{array}{l}\text { Local radiation therapy }>= \\
\text { 50Gy }\end{array}$ & 1.22 & $0.48-3.31$ & 0.68 \\
\hline Chemotherapy & 1.86 & $0.74-4.62$ & 0.18 \\
\hline \multicolumn{4}{|c|}{ Multivariate analysis of OS among all tumors } \\
\hline WHO grade3 & 3.49 & $0.91-23.05$ & 0.07 \\
\hline PFA & 3.54 & $1.33-11.4$ & 0.01 \\
\hline
\end{tabular}

resection was not significantly associated with survival, even though there was a tendency towards predicting shorter survival among all ependymomas or in PFA or PFB (Additional file 15 Figure S9; Discussion). Multivariate analysis using Cox regression of the same set of clinical factors and molecular markers showed that PFA was the only factor that was independently associated with PFS and OS among all EPNs ( $p=0.002$ for PFS; $p=0.01$ for OS; Table 2). Univariate and multivariate analyses of the tumors in each location are described (Additional file 12 Table S6).

Finally, the efficacy of molecular classification in predicting prognosis in EPN patients was investigated separately for ST- or PF-EPN patients. No significant difference in 
survival was observed between the C11orf95-RELA fusion positive and negative ST-EPNs (Fig. 3a, b). Survival data was not available for EP116. Patients with PFA tumors showed a tendency towards shorter progression free survival ( $p=0.06$, Fig. 3c) and significantly shorter overall survival ( $p=0.009$, Fig. $3 \mathrm{~d})$ than those with PFB tumors. Among patients with PFA, those with 1q gain showed significantly shorter PFS than those without $1 \mathrm{q}$ gain $(p=0.02$; Fig. 3e). There was no significant difference in overall survival between PFA patients with and without 1q gain ( $p=0.44$, Fig. 3f).

PF-EPN subgroup prediction by methylation thresholds of the three genes

Next, we developed a PF-EPN subgroup prediction assay using DNA methylation percentage thresholds for CRIP1, $D R D 4$, and $L B X 2$. $\mathrm{R}$ version 3.4.3 ( $\mathrm{R}$ Foundation for
Statistical Computing, Vienna, Austria) was used for all analyses. In the training process, likelihoods for each gene and subgroup were calculated using the training dataset assuming beta distribution, and thresholds for each gene were determined to be 25,11 , and $23 \%$, respectively based on the likelihood ratio (Figs. 4a, b). In the validation process, prediction results for each gene were obtained from both training and validation datasets, and three rule candidates were validated by the results (Additional file 3 Table S3, Additional file 13 Table S5; Additional file 4 Figure S5b). The first of the three candidates classified a case as PFB if all of genes suggested PFB, the second classified a case as PFB if a majority of genes suggested PFB and the last classified a case as PFB if any gene suggested PFB. All candidates classified a case as PFA if they did not classify it as PFB. Finally, a rule candidate that classified a case as PFB if all three genes suggested a

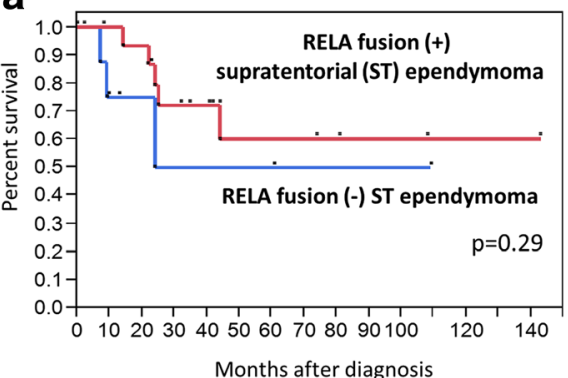

C
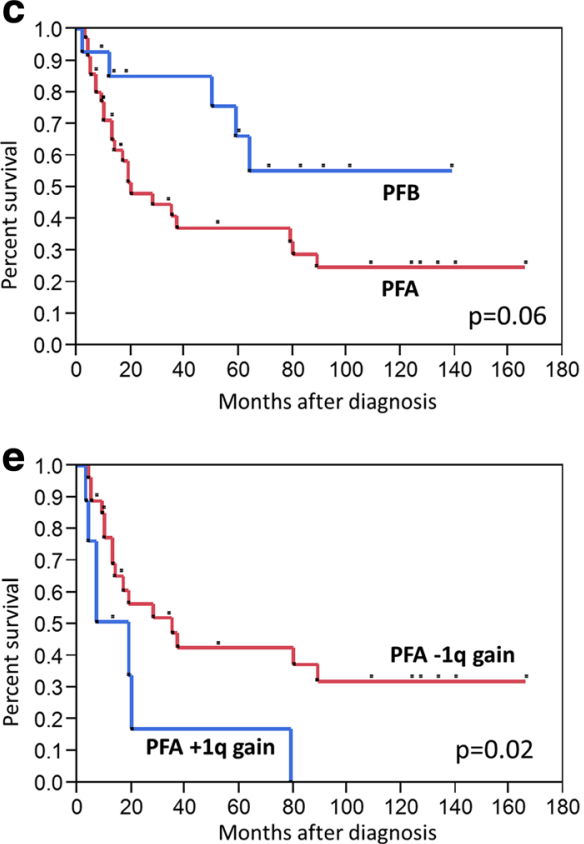

b

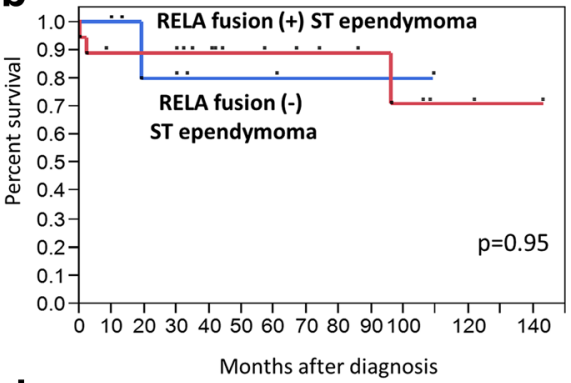

d

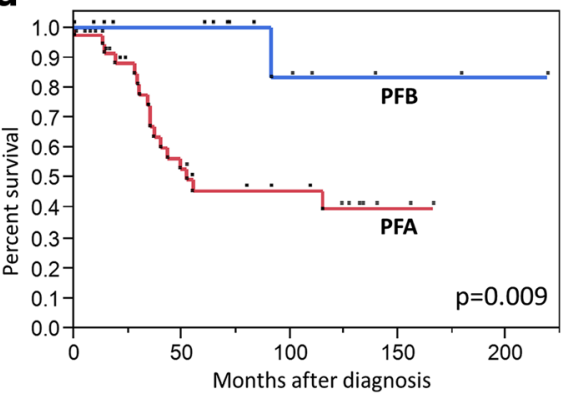

f

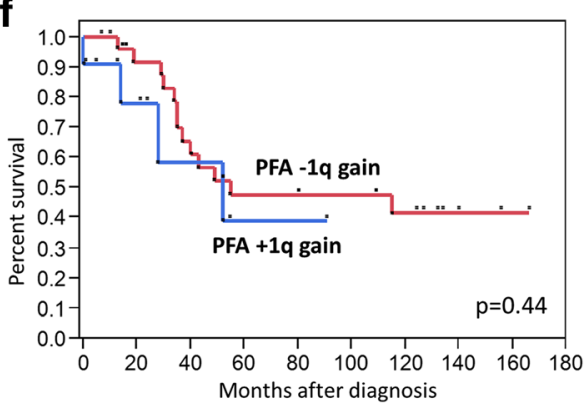

Fig. 3 Survival of ST-EPNs stratified according to the presence of C110rf95-RELA fusions. a Progression-free survival (PFS), b overall survival (OS). There was no survival difference between the two groups. (c-d) PFS (c) and OS (d) of PFA and PFB. Significant differences in OS ( $p=0.009)$ were observed between PFA and PFB patients. (e-f) PFS (e) and OS (f) of PFA with or without 1q gain. A significant difference in PFS ( $p=0.02)$ but not in OS was observed between them 

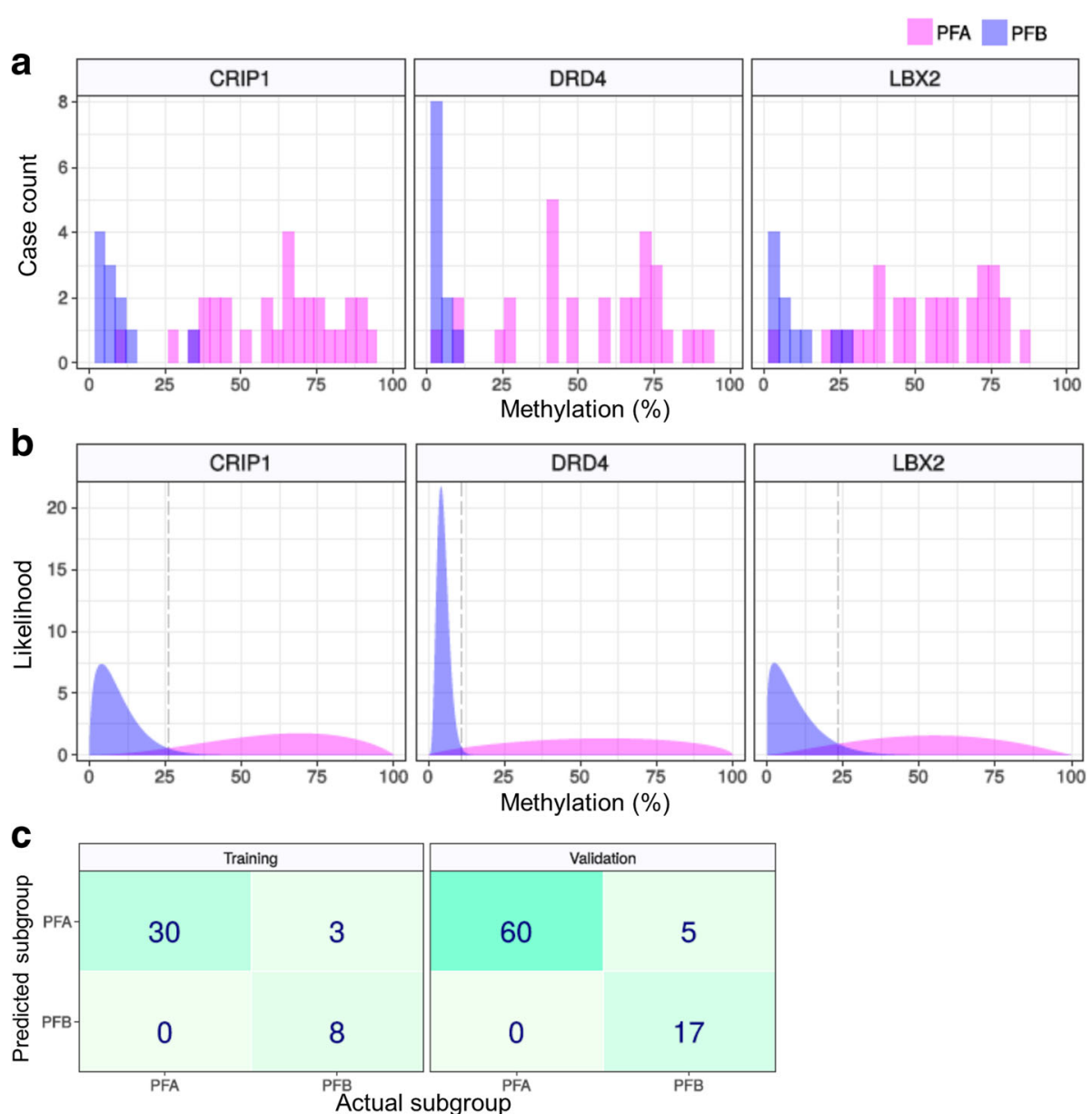

Fig. 4 Prediction of PF-EPN subgroups using methylation thresholds of CRIP1, DRD4, and LBX2. a Methylation percentages for the three genes in the training dataset. $\mathbf{b}$ Likelihoods for each subgroup calculated by presuming beta distribution. The long-dashed lines denote thresholds determined by likelihood ratios. c Confusion matrices of prediction with training and validation datasets, according to the rule that classifies a case as PFB if all three genes suggest PFB

PFB was defined as the prediction rule, which showed highest specificities for PFB in the both datasets (training: 1.0, validation: 1.0) (Fig. 5c; Additional file 13 Table S5). Our results thus indicated that the methylation status of these three genes may predict the molecular subgroup of PF-EPNs with $100 \%$ specificity for PFB.

\section{Immunohistochemical analysis of H3K27me3 for PF-EPNs}

Finally, we determined the relationship between H3K27me3 immunostaining and molecular subclassification of PF-EPNs based on the $450 \mathrm{~K}$ array. The 44 JPMNG cases whose H3K27me3 immunostaining results were available were classified either as intact or reduced expression by two pathologists (A.Y. and K.S). These studies showed that all 29 (100\%) PFA cases showed reduced expression of H3K27me3, while 13 out of 15 (86.7\%) and 2 out of 15 (13.3\%) of PFB cases showed intact and reduced H3K27me3 expression, respectively. Among 29 PFA cases, which showed reduced H3K27me3 immunoreactivity, less than
$5 \%$ of tumor cells in 11 cases showed H3K27me3 expression (Fig. 5a) and 5-50\% tumor cells in 18 cases showed H3K27me3 labeling (Fig. 5b). In contrast, among the 15 PFB cases, 13 retained intact H3K27me3 expression (Fig. 5c), whereas 2 showed labeling, categorized as reduced expression, in 10-60\% of cells (Fig. 5d). Thus, when a cutoff of $80 \%$ labeled nuclei was used as suggested by Panwalkar et al. [26], intact (> 80\%) H3K27me3 expression predicted PFB with $100 \%$ specificity (Fig. $5 e, f)$.

\section{Discussion}

Molecular classification is essential for integrated diagnosis of central nervous system tumors in modern diagnostic pathology. However, using such classification in ependymomas is challenging due to the very limited number of available markers. In this study, the proposed molecular classification of supratentorial and posterior fossa ependymomas was extensively investigated in an independent set of 113 locally diagnosed ependymal tumors in Japan. 

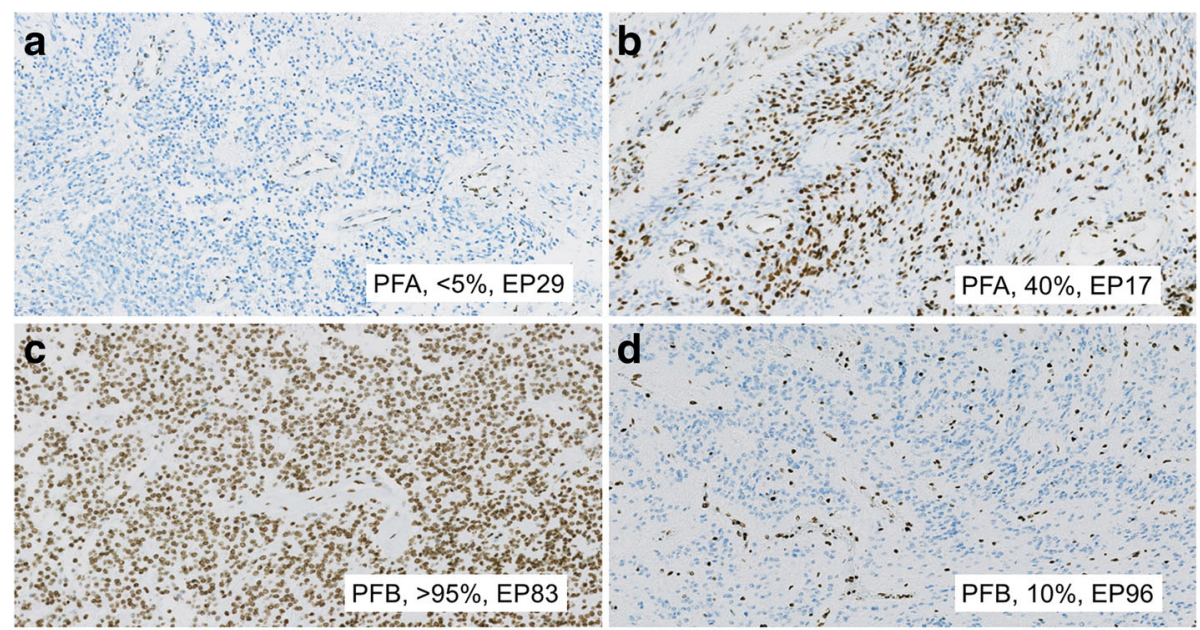

e

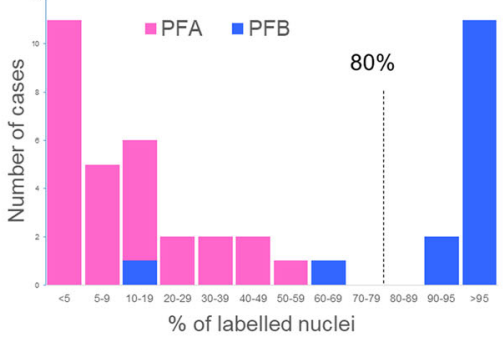

f

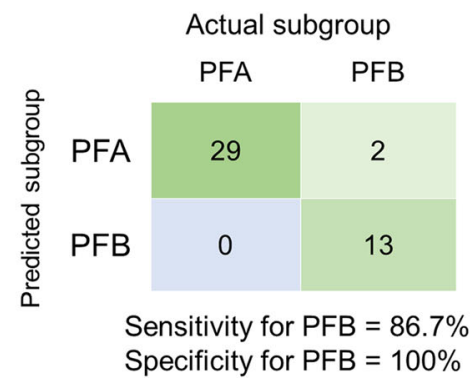

Fig. 5 Immunohistochemistry for H3K27me3 in PFA and PFB tumors. All PFA tumors demonstrated reduced H3K27me3 expression (80\% or less). Approximately $38 \%$ of them showed reactivity in less than $5 \%$ of tumor cells $(\mathbf{a}, \mathbf{e})$, and the remaining cases showed labeling in $5-50 \%$ of tumor cells (b, e). In contrast, most PFB tumors retained intact H3K27me3 expression (> 80\% labeled nuclei) (c, e). A few PFB tumors, however, showed labeling in 10-60\% of cells, which were categorized as reduced expression of H3K27me3 (d, e). e, a histogram of the percentage of labeled nuclei in PFA and PFB tumors. $\mathbf{f}$, a confusion matrix for actual and predicted subgroup by H3K27me3 immunohistochemistry when PFB was defined as intact H3K27me3 expression and PFA as reduced expression

Our study confirmed that C11orf95-RELA fusion is a unique genetic feature of ST-EPN and that its presence is consistent with histopathological diagnosis. On the other hand, pathogenesis of ST-EPN in the absence of C11orf95-RELA fusion remains unresolved. There were 9 C11orf95-RELA fusion-negative ST-EPNs including 4 ependymoma grade IIs and 5 anaplastic ependymoma grade IIIs. Thus, those tumors were histologically confirmed as ependymoma, by definition. None of these were diagnosed as subependymoma following central review, where only a single case of YAP1 fusion was identified by FISH (EP117). Instead, 2 novel fusion genes, EP300-BCORL1 and FOXO1-STK24, were detected in single cases (EP3 and EP57).

$E P 300$ (E1A binding protein p300, located at 22q13) is a transcriptional coactivator that binds to a variety of transcription factors and bridges them to basal transcription machinery, and additionally functions as histone acetyltransferase that relaxes chromatin structure [5]. BCORL1 (BCL6 Corepressor Like 1, located Xq26.1) is a transcriptional corepressor that interacts with histone deacetylases to repress transcription of genes such as E-cadherin [23].
The EP300-BCORL1 fusion found in EP3 retained nearly all functional domains of both genes, but BCORL1 expression was significantly increased in EP3 (Additional file 10 Figure S8). Interestingly, 2 ossifying fibromyxoid tumors with a CREBBP-BCORL1 fusion have been reported [12]. CREBBP $(C B P)$ is a paralog of $E P 300$ and as their functions mostly overlap they are often collectively described as $C B P / E P 300$ ) [5]. BCORL1 was overexpressed in CREBBP1-BCORL1 fusion-positive tumors, suggesting that activation of BCORL1 may be a consequence of CREBBP1-BCORL1. Thus, it is likely that $B C O R L 1$ activation, a consequence of EP300-BCORL1, may lead to deregulation of chromatin remodeling through recruitment of histone deacetylase. In addition, BCOR (BCL6 corepressor) internal tandem duplication (ITD), which acts as an activating oncogene [34], was also found in a single ST-EPN in our cohort (EP116). The DKFZ classifier matched the BCOR ITD tumor to "CNS high grade neuroepithelial tumor with $B C O R$ alteration (CNS HGNET-BCOR)" with a high score (0.99). The BCORL1-fusion tumor was interpreted by the DKFZ classifier as a 'no match', although it was also classified as CNS HGNET-BCOR with a low 
score (0.44) (Fig. 1, Additional file 3 Table S3). Thus it is likely that these tumors may belong to a new entity within the unclassified heterogeneous high grade neuroectodermal/glial tumors of children [30]. An HDAC inhibitor may potentially be effective for tumors with activated BCOR/BCORL1.

Much less is known about the FOXO1-STK24 fusion found in another ST-EPN (EP57). FOXO1 is a transcription factor that is involved in the maintenance of cellular homeostasis [36]. PAX3-FOXO1 fusion, which acts as a highly activated transcription factor, is found in $60 \%$ of alveolar rhabdomyosarcomas [36]. STK24 (also known as MST3) is a serine-threonine kinase that functions upstream of the mitogen-activated kinase (MAK) signaling pathway. STK24/MST3 is overexpressed in breast cancers and promotes proliferation and tumorigenicity [30]. Recurrent mutations or fusions of STK24 have not been reported. The DKFZ classifier found no match for this ST-EPN tumor (classified as PFB, score $=0.44$ ). Interestingly, this tumor showed copy number oscillation compatible with chromothripsis on chromosomes 13, on which FOXO1 and STK24 are located, strongly suggesting that this may be the mechanism underlying the gene fusion. Both FOXO1 and STK24 were overexpressed in EP57 (Additional file 10 Figure S8), suggesting that either of them may carry an oncogenic property. Although a detailed study of individual cases is beyond the scope of this paper, this tumor may warrant further investigation.

None of the other RELA fusion-negative ST-EPN were classifiable even with the DKFZ classifier. In summation, our findings suggest that RELA/YAP1 fusion-negative ST-EPNs may be a heterogeneous group of tumors that consist of a variety of mutations or rare fusion genes, which are unlikely to belong to a single category. Further studies using a vast number of tumors may help in clarifying whether tumors with similar genetic changes and/ or DNA methylation profiles truly define a new tumor entity. Considering the high homogeneity of RELA-fusion positive ST-EPNs, it is doubtful whether these are biologically equivalent to ependymoma. According to the latest WHO Classification [8], ependymomas are primarily diagnosed via histology. As such, they may be diagnosed as ependymomas, at least for the time being. Nonetheless, it is important to be aware that histologically diagnosed RELA-fusion negative ependymomas may have a biology which is different from that of quintessential RELA-fusion positive ependymomas. Further molecular classification and incorporation into future WHO Classification criteria is warranted.

In contrast to a previous large series, no significant association between the presence of C11orf95-RELA fusion and patient survival was noticed in our series [25]. Furthermore, RELA fusion status was reportedly not related to a significant difference in the survival of ST-EPN patients
[9]. In addition, the rate of GTR in RELA fusion-positive ST-EPN was not statistically significant compared to that in RELA fusion-negative ST-EPN $(p=0.55)$ in our cohort. The impact of C11orf95-RELA fusion on patient survival needs to be further investigated. These findings may reflect the fact that RELA fusion-negative ST-EPNs are a biologically heterogeneous group of tumors. Interestingly, median progression-free or overall survival was not reached for C11orf95-RELA fusion positive ST-EPNs. Other proposed prognostic molecular markers of ependymomas include TERT and EZH2 expression [18, 21, 31]. Although we confirmed elevated EZH2 and TERT expression in RELA fusion-positive ST-EPNs, they were not associated with patient survival. Nonetheless, it may be of interest that TERT mRNA expression was elevated in RELA fusion-positive ST-EPNs, to an extent which far exceeded that in glioblastomas with TERT promoter mutations (Additional file 9 Figure S4b). None of the ST- or PF-EPNs in this cohort carried the TERT promoter mutation (data not shown). This phenomenon has also been described elsewhere [10]. Costelo-Branco et al., found that the methylation status of some CpG sites upstream of transcription starting site of TERT, were positively correlated with TERT mRNA expression in childhood malignant brain tumors and were also associated with the prognosis of patients with PF ependymoma [5]. Although neither TERT mRNA expression nor TERT UTSS methylation was associated with patient prognosis in this series, TERT UTSSs were highly methylated in the RELA fusion-positive ST-EPNs with elevated TERT mRNA expression. The mechanism of TERT upregulation appears to be complex and warrants further investigation.

We validated the proposed molecular classification of PF-EPN for efficacy in predicting clinical characteristics including that of patient survival. The $450 \mathrm{~K}$ analysis accurately classified the published reference PF-EPN dataset, confirming the robustness of the analysis. PFA showed a minor but significant increase in methylation levels and distinct methylation profiles when compared to PFB (Fig. 2). With a few exceptions, PFA patients were mostly infants and the ages of the PFB patients were significantly higher than those of PFA (Additional file 14 Figure S3a). PFA tumors showed significantly more lateral extension compared to PFB, most of which were medially located (Additional file 14 Figure S3b). DKFZ classifier results were mostly consistent with our analysis with a few exceptions. Two PFAs showed no match. One PFB (EP96) was classified as pituitary adenoma and another PFB (EP86) as myxopapillary ependymoma. These classifications were not compatible with their histology or location.

Our multivariate analysis using Cox regression showed that the PFA subgroup was the only molecular marker which was independently associated with patient PFS 
and OS among all ependymomas. Among PF-EPN, PFA patients showed significantly shorter PFS and OS compared to PFB patients. These findings corroborated previous reports $[19,29]$ and consolidated the significance of proposed molecular classification, indicating that PFA and PFB may be biologically distinct subgroups of PF-EPN. The important clinical implication of the PFA/PFB classification is its potential to aid therapeutic decision making. Based on the results of a study conducted on a large series of PF-EPN, Ramaswamy suggested that a substantial proportion of totally resected PFB patients may be treated with surgery alone, without radiotherapy [29]. Although this suggestion needs to be tested in a randomized clinical trial, it is evident that molecular classification may play an important role in the clinical management of ependymomas. Although resection rate was not significantly associated with survival in our survival analysis, there was a tendency for gross total resection (GTR) to predict longer survival (Additional file 15 Figure S9). This may be due to the relatively small number of cases screened in the study. Retrospectively, the extent of resection although determined locally was not centrally reviewed which may be a limitation of the multi-institutional nature of the study. Data from the Collaborative Ependymoma Research Network (CERN), which was also a multi-institutional study, did not indicate statistically significant differences in PFA survival due to resection rate [29]. A prospective clinical trial for ST-and PF-EPN with molecular classification and a standardized central review for the extent of resection is on-going in Japan Children's Cancer Group (JCCG).

In spite of its usefulness, a practical problem associated with methylation classification, is its cost as well as limited availability as a routine diagnostic test. To overcome this issue, a simplified methylation test was developed to determine PFA/PFB for PF-EPNs by examining the 3 most highly methylated regions in PFA via pyrosequencing and rigorously validating it by using an extended PF-EPN cohort of 123 PF-EPNs which combined our cases and an independent set of samples from Toronto (Results and Fig. 5). With this novel assay, we were able to diagnose PFB with $100 \%$ specificity. We also confirmed the efficacy of anti-H3K27me3 immunohistochemistry, recently reported by Panwalkar et al. [26], by predicting PFB with $100 \%$ specificity in a selected Japanese cohort of 44 PF-EPNs (Fig. 5 ). It may be noteworthy, that the proposed cutoff of $80 \%$ for H3K27me3 immunohistochemistry, though appropriate, may prove to be somewhat counterintuitive for judging reduced PFA expression. Among the 4 PFBs examined via both methods, certain single cases were misclassified as PFA in each method. Although methylation assessment at individual CpG sites has its own limitation such as potential heterogeneity of methylation across CpGs as well as masking by co-existing non-neoplastic cells, these assays may serve as clinically applicable techniques for rapid molecular classification of PF-EPN, which are also suitable for risk-grouping in clinical trials. Hopefully, these may lead to better treatment decision making for the ependymoma patients in the future.

It has been suggested that the presence of 1q gain is associated with poor prognosis in ependymomas $[13,16$, 24, 25]. A large cohort study indicated significant differences in PFS between patients with and without 1q gain in both PFA and PFB, whereas significantly shorter overall survival in patients with 1q gain was seen only in PFA patients but not in PFB or ST-EPN-RELA patients $[6,24,25]$. In our cohort, 1q gain was highly enriched in a subset of PFA, while only PFB had 1q gain (Fig. 2). PFA patients with 1q gain were older at onset $(p<0.001$; Fig. 3a) and exhibited significantly shorter PFS than those without 1q gain ( $p=0.016$, Fig. 4e). However, there was no significant difference of OS between those patients $(p=0.51$, Fig. 4f). The reason for discrepancies related to the impact of 1q gain on OS of PF-EPN between our study and others is currently unknown. It has been recently proposed that PFA and PFB may further be divided into 9 or 5 subgroups [6, 24]. Although our cohort was too small to validate such subgrouping, it is likely that PF-EPN are a heterogeneous group of tumors. The significance of molecular markers/subgroups in patient prognosis needs to be examined by a prospective study.

Our study demonstrated that histopathological diagnosis of ependymomas such as ST-EPN is often challenging. Eight locally diagnosed ST-EPNs were re-classified as non-EPN tumors following a pathology review. None of them carried RELA-fusion. The significance of WHO grading of ependymomas is highly controversial $[7,25]$. On the other hand, our histopathological review classified most PFA as WHO grade III, and PFB as WHO grade II. Current WHO Classification bases the diagnosis of ependymomas solely on the histopathology of tumors. Thus the role of histopathology needs to be revisited.

\section{Conclusion}

Our results showed that C11orf95-RELA fusion is a unique and highly specific diagnostic marker for ST-EPN. However, histologically verified RELA fusion- or YAP1 fusion-negative ST-EPN also exists. These cases were neither histologically nor molecularly subependymomas, and thus did not fall into any of the 3 proposed molecular groups of ST-EPN [25]. They appear to be a very heterogeneous group of tumors distinct from the RELA fusionpositive ST-EPN, and are unlikely to fall into a single category. However, most if not each one of them may rather belong to different, possibly new entities, considering the DKFZ classifier results. A more thorough implementation of molecular diagnosis may hopefully resolve unanswered 
questions. While the definition of ependymoma awaits future discussion, it is clear that histology alone may not be sufficient for a perfect definition of this disease. Although the true clinical impact of molecular classification, especially for therapeutic decision making, needs to be determined in a prospective clinical trial, our study clearly demonstrated that molecular classification may hold the key to future management of ependymomas.

\section{Additional files}

Additional file 1: Table S1. Primer sequences and pyrosequencing assays (XLSX $14 \mathrm{~kb}$ )

Additional file 2: Table S2. Candidate probes in screening set for pyrosequencing assay (XLSX $11 \mathrm{~kb})$

Additional file 3: Table S3. List of cases (XLSX $66 \mathrm{~kb}$ )

Additional file 4: Figure S5. Methylation percentages for CRIP1, DRD4, and $L B X 2$ in datasets. (a) Methylation percentages for the three genes in the original dataset of JPMNG and SickKids. (b) Methylation percentages for the three genes in the validation dataset. The dashed lines denote the thresholds determined by likelihood ratio in the training process. (TIF $6463 \mathrm{~kb}$ )

Additional file 5: Table S4. RNA sequencing results (XLSX $51 \mathrm{~kb}$ ) Additional file 6: Figure S1. (a) Electropherograms of novel fusion transcripts detected in ST-EPNs. (b) Copy number analysis of EP57 showing copy number oscillation in chromosome 6 and 13 (The DKFZ Classifier output, molecularneuropathology.org). (TIF $7893 \mathrm{~kb}$ )

Additional file 7: Figure S6. (a) (b) Copy number plots of EP33 showing loss of upstream exon2 of RELA. (c) Immunohistochemical staining of $L 1$ cell adhesion molecule (L1CAM) presents strong positivity in EP33. (TIF $9820 \mathrm{~kb}$ )

Additional file 8: Figure S7. Histological features in RELA-negative/ YAP1-negative supratentorial ependymoma cases. EP3 (EP300-BCORL1 fusion-positive) exhibits typical findings of anaplastic ependymoma, including hypercellularity, perivascular pseudorosettes (a), calcification (arrows, b) and high MIB-1 labeling index (c). In EP57 (FOXO1-STK24 fusion-positive), perivascular pseudorosettes (d), calcification (arrows, e), microcyst formation (e), vacuolated cells (f), GFAP-positive cells (g), EMA positive reaction (h) and low MIB-1 labeling index (i) were observed. (TIF 58932 kb)

Additional file 9: Figure S4. Box plots showing EZH2 (a), TERT expression (b), and methylation status of upstream transcription starting site of TERT (c). Significant upregulation of these markers in C110rf95-RELA fusion positive EPNs was observed. (TIF $2376 \mathrm{~kb}$ )

Additional file 10: Figure S8. Expression data of (a) EP300, (b) BCORL1, (c) FOXO1, and (d) STK24 among supratentorial ependymomas. EP3 and EP57 show by far the highest expression levels of BCORL1 and FOXO1 among all ST-EPNs, respectively. (TIF $5041 \mathrm{~kb}$ )

Additional file 11: Figure S2. Classification of posterior fossa (PF-EPN) and spinal ependymomas (SP-EPN) using genome-wide methylation profiling. A heatmap analyzed by 3932 probes that showed high standard deviations ( $\mathrm{SD}>0.25$ ) on $\mathrm{CpG}$ islands for unsupervised hierarchical clustering of 72 centrally-diagnosed posterior and spinal ependymoma samples shows that nearly all spinal tumors except one (EP114) were clustered with posterior fossa PFB. The following information is indicated below the heatmap: tumor location, a pattern of PF tumors extension, pathological grading, the presence of 1q gain, age at onset, and the DKFZ classifier result. (TIF $6031 \mathrm{~kb}$ )

Additional file 12: Table S6. Univariate and multivariate analysis of ST and PF ependymomas in PFS and OS. (DOCX $44 \mathrm{~kb}$ )

Additional file 13: Table S5. Validation results of PF-EPN subgroup prediction rule candidates. (DOCX $16 \mathrm{~kb}$ )

Additional file 14: Figure S3. Comparison of clinical characteristics between posterior fossa PFA and PFB. (a) Box plot showing the distribution of the patients' age at onset. (b-d) Mosaic plot for tumor location, pathological grading, and resection rate in posterior fossa tumors. Comparison of clinical characteristics of PFA stratified by the presence of 1q gain. (e) Box plot showing the distribution of the patients' age at onset. (f-h) Mosaic plot of tumor location, dissemination at onset, and resection rate in PFA tumors. (TIF $6273 \mathrm{~kb}$ )

Additional file 15: Figure S9 Progression-free survival (PFS, $a, c, e, g, i)$ and overall survival (OS, b, d, f, h, j) of histologically verified all-EPNs $(a, b)$, ST-EPNs (c, d), PF-EPNs (e, f), PFA-EPNs $(g, h)$, and PFB-EPNs (i, j) stratified according to the extent of resection. (TIF $32224 \mathrm{~kb}$ )

Additional file 16: The Japan Pediatric Molecular Neuro-Oncology Group (JPMNG): participating centers and departments. (DOCX 17 kb)

\section{Abbreviations}

EPN: Ependymoma; FISH: Fluorescent in situ hybridization;

GBM: Glioblastoma; PF-EPN: Gosterior fossa ependymoma; RT-PCR: Reverse transcription- polemerase chain reaction; SP-EPN: Spinal ependymoma; STEPN: Supratentorial ependymoma

\section{Acknowledgements}

This study was conducted as a part of the Japan Molecular Neuro-Oncology Group (JPMNG) study, a project jointly supported by Japan Society for Neuro-Oncology and Japan Society for Pediatric Neurosurgery. The full list of the centers participating JPMNG is shown in Additional file 16 information. The authors thank all patients and physicians who contributed to this study. The authors thank Sachiko Miura, Chizu Kina and Toshiko Sakaguchi for superb technical assistance. This work is dedicated to the memory of Dr. Mami Yamasaki, who was one of the founding members of JPMNG and inspired us all to form a nationwide collaboration on pediatric brain tumors.

\section{Availability of data and material}

The genome-wide DNA methylation data generated during the current study are available in NCBI's Gene Expression Omnibus and are accessible through GEO Series accession number GSE114523 (https:// www.ncbi.nlm.nih.gov/ geo/query/acc.cgi?acc=GSE114523). Methylation data of 48 EPNs (GSE42752) and 6 normal cerebellums (GSE44684) $[17,19,33]$ were obtained from the Gene Expression Omnibus database (http://www.ncbi.nlm.nih.gov/geo/) for comparison with our data.

\section{Funding}

This work was supported in part by Grants-in-Aid for Scientific Research (KAKENHI (Multi-year Fund)) from the Japan Society for the Promotion of Science (JSPS) Grant No. 16 K10775 (K.I.) and No. 17 K15659 (K.S.), and the Practical Research for Innovative Cancer Control from Japan Agency for Medical Research and Development, AMED Grant No. JP17ck0106168 (T.K.).

\section{Authors' contributions}

KF designed, carried out and interpreted all experiments, and wrote the manuscript YK established JPMNG, collected and organized samples and patients' information TS organized samples and patients' information SF, SY and TU performed methylation analysis DN and MK performed statistical analysis MHK, KY, YN, AT, TN, HT and YM organized samples and patients' information and carried out experiments $\mathrm{HI}$ and TK helped RNA sequencing $A S, J H, T H, T K, K S$ and $A Y$ performed histopathological review TS, HN, KM, YS, RS, TT, YM, KK, M.N, TF, MN, YN, YH, SO, AW, KS, KK, ID, JF, YM, NK, AK, MY, NN, TW, MY, NT, TU, MT, YN, TA, SI, MN, KY, YK and MM provided samples and patients' information TO contributed in writing and valuable discussion VR and MDT provided the Toronto cohort of ependymomas and their molecular information SS, MY, HA, HS and RN established JPMNG and organized nationwide collaboration $\mathrm{KI}$ initiated the project, established and organized JPMNG, supervised and interpreted experiments, and wrote the manuscript. All authors except MY contributed to writing of the manuscript. All authors read and approved the final manuscript.

\section{Ethics approval and consent to participate}

This study was approved by the ethics committees of the National Cancer Center (2013-042) as well as the respective local institutional review boards. Consent to participate to the study was obtained whenever applicable.

\section{Consent for publication}

Not applicable. 


\section{Competing interests}

K.I. is a recipient of a research grant from Chugai Pharmaceuticals/EPS Co., Ltd., Eisai Co., Ltd., and Daiichi Sankyo Co., Ltd. for projects unrelated to this work. The authors' declare that they have no competing interests

\section{Publisher's Note}

Springer Nature remains neutral with regard to jurisdictional claims in published maps and institutional affiliations.

\section{Author details}

${ }^{1}$ Division of Brain Tumor Translational Research, National Cancer Center Research Institute, 5-1-1 Tsukiji, Chuo-ku, Tokyo 104-0045, Japan. ${ }^{2}$ Department of Neuro-Oncology/Neurosurgery, Saitama Medical University International Medical Center, Hidaka, Saitama, Japan. ${ }^{3}$ Department of Biomedical Research and Innovation, Institute for Clinical Research, Osaka National Hospital, National Hospital Organization|, Osaka, Japan. ${ }^{4}$ Department of Neurosurgery, Osaka National Hospital, National Hospital Organization, Osaka, Japan. ${ }^{5}$ Division of Epigenomics, National Cancer Center Research Institute, Tokyo, Japan. ${ }^{6}$ Department of Bioinformatics, National Cancer Center Research Institute, Tokyo, Japan. ${ }^{7}$ Department of Clinical Genomics, National Cancer Center Research Institute, Tokyo, Japan. ${ }^{8}$ Division of Genome Biology, National Cancer Center Research Institute, Tokyo, Japan. ${ }^{9}$ Department of Pathology, Saitama Medical University, Saitama, Japan. ${ }^{10}$ Department of Pathology, Gunma University Hospital, Maebashi, Gunma, Japan. ${ }^{11}$ Department of Diagnostic Pathology, Hyogo Cancer Center, Kobe, Hyogo, Japan. ${ }^{12}$ Department of Laboratory Medicine and Pathology (Neuropathology), Tokyo Metropolitan Neurological Hospital, Tokyo, Japan. ${ }^{13}$ Department of Pathology and Clinical Laboratories, National Cancer Center Hospital, Tokyo, Japan. ${ }^{14}$ Department of Pediatric Hematology and Oncology, Osaka City General Hospital, Osaka, Japan. ${ }^{15}$ Department of Neurosurgery, Graduate School of Medicine, Yokohama City University, Fukuura, Kanagawa, Japan. ${ }^{16}$ Department of Neurosurgery, Faculty of Medicine, The University of Tokyo, Tokyo, Japan. ${ }^{17}$ Department of Neurosurgery and Neurooncology, National Cancer Center Hospital, Tokyo, Japan. ${ }^{18}$ Department of Neurosurgery, Kurume University School of Medicine, Kurume, Fukuoka, Japan. ${ }^{19}$ Department of Neurosurgery, Faculty of Life Sciences, Kumamoto University Graduate School, Kumamoto, Japan. ${ }^{20}$ Department of Neurosurgery, Yamagata University School of Medicine, Yamagata, Japan. ${ }^{21}$ Department of Neurosurgery, Tohoku University Graduate School of Medicine, Sendai, Japan. ${ }^{22}$ Department of Pediatric Neurosurgery, Osaka City General Hospital, Osaka, Japan. ${ }^{23}$ Department of Neurosurgery, Kyorin University Faculty of Medicine, Tokyo, Japan. ${ }^{24}$ Department of Neurosurgery, Graduate School of Medical Sciences, Kanazawa University, Kanazawa, Japan. ${ }^{25}$ Department of Pathology, Kurume University, Kurume, Fukuoka, Japan. ${ }^{26}$ Department of Neurosurgery, Fujita Health University, Toyoake, Aichi, Japan. ${ }^{27}$ Department of Neurosurgery, Showa University School of Medicine, Tokyo, Japan. ${ }^{28}$ Department of Neurological Surgery, Dentistry and Pharmaceutical Sciences, Okayama University Graduate School of Medicine, Okayama, Japan. ${ }^{29}$ Department of Neurological Surgery, Wakayama Medical University, Wakayama, Japan. ${ }^{30}$ Department of Neurosurgery, Nagano Children's Hospital, Nagano, Japan. ${ }^{31}$ Department of Neurosurgery, Osaka University Graduate School of Medicine, Osaka, Japan. ${ }^{32}$ Department of Neurosurgery, Hyogo Prefectural Kobe Children's Hospital, Kobe, Hyogo, Japan. ${ }^{33}$ Department of Pathology, Hyogo Prefectural Kobe Children's Hospital, Kobe, Hyogo, Japan. ${ }^{34}$ Department of Neurosurgery, Tazuke Kofukai Foundation, Medical Research Institute and Kitano Hospital, Osaka, Japan. ${ }^{35}$ Department of Neurosurgery, Shizuoka Children's Hospital, Shizuoka, Japan. ${ }^{36}$ Department of Pediatrics, The Jikei University School of Medicine, Tokyo, Japan. ${ }^{37}$ Department of Neurosurgery, University of Occupational and Environmental Health, Kitakyushu, Fukuoka, Japan. ${ }^{38}$ Department of Neurosurgery, Kanazawa Medical University, Kanazawa, Japan. ${ }^{39}$ Department of Neurosurgery, Toyama University Hospital, Toyama, Japan. ${ }^{40}$ Department of Neurosurgery, Faculty of Medicine, Kinki University, Osaka, Japan. ${ }^{41}$ Department of Neurosurgery, Kansai Medical University, Hirakata, Osaka, Japan. ${ }^{42}$ Department of Neurosurgery, Hokkaido Medical Center for Child Health and Rehabilitation, Sapporo, Japan. ${ }^{43}$ Department of Pathology and Applied Neurobiology, Graduate School of Medical Science, Kyoto Prefectural University of Medicine, Kyoto, Japan. ${ }^{44}$ Department of Pathology, Osaka National Hospital, National Hospital Organization, Osaka, Japan.

${ }^{45}$ Developmental \& Stem Cell Biology Program, The Hospital for Sick Children, Toronto, ON, Canada. ${ }^{46}$ Division of Neurosurgery, Hospital for Sick
Children, Toronto, ON, Canada. ${ }^{47}$ Department of Neurosurgery, Teikyo University Hospital, Mizonokuchi, Kanagawa, Japan. ${ }^{48}$ Department of Pediatric Neurosurgery, Takatsuki General Hospital, Takatsuki, Osaka, Japan.

${ }^{49}$ Department of Neurosurgery, Juntendo University, Tokyo, Japan.

\section{Received: 2 November 2018 Accepted: 3 November 2018} Published online: 04 December 2018

\section{References}

1. Arita H, Narita Y, Fukushima S, Tateishi K, Matsushita Y, Yoshida A, Miyakita Y, Ohno M, Collins VP, Kawahara N, Shibui S, Ichimura K (2013) Upregulating mutations in the TERT promoter commonly occur in adult malignant gliomas and are strongly associated with total 1p19q loss. Acta Neuropathol 126:267-276. https://doi.org/10.1007/s00401-013-1141-6

2. Arita H, Narita $Y$, Matsushita $Y$, Fukushima S, Yoshida A, Takami H, Miyakita $Y$, Ohno M, Shibui S, Ichimura K (2015) Development of a robust and sensitive pyrosequencing assay for the detection of IDH1/2 mutations in gliomas. Brain Tumor Pathol 32:22-30. https://doi.org/10.1007/s10014-014-0186-0

3. Arita H, Narita $Y$, Takami H, Fukushima S, Matsushita Y, Yoshida A, Miyakita $Y$, Ohno M, Shibui S, Ichimura K (2013) TERT promoter mutations rather than methylation are the main mechanism for TERT upregulation in adult gliomas. Acta Neuropathol 126:939-941. https://doi.org/10.1007/s00401-013-1203-9

4. Capper D, Jones DTW, Sill M, Hovestadt V, Schrimpf D, Sturm D, Koelsche C, Sahm F, Chavez L, Reuss DE, Kratz A, Wefers AK, Huang K, Pajtler KW, Schweizer L, Stichel D, Olar A, Engel NW, Lindenberg K, Harter PN, Braczynski AK, Plate KH, Dohmen H, Garvalov BK, Coras R, Holsken A, Hewer E, Bewerunge-Hudler M, Schick M, Fischer R, Beschorner R, Schittenhelm J, Staszewski O, Wani K, Varlet P, Pages M, Temming P, Lohmann D, Selt F, Witt H, Milde T, Witt O, Aronica E, Giangaspero F, Rushing E, Scheurlen W, Geisenberger C, Rodriguez FJ, Becker A, Preusser M, Haberler C, Bjerkvig R, Cryan J, Farrell M, Deckert M, Hench J, Frank S, Serrano J, Kannan K, Tsirigos A, Bruck W, Hofer S, Brehmer S, Seiz-Rosenhagen M, Hanggi D, Hans V, Rozsnoki S, Hansford JR, Kohlhof P, Kristensen BW, Lechner M, Lopes B, Mawrin C, Ketter R, Kulozik A, Khatib Z, Heppner F, Koch A, Jouvet A, Keohane C, Muhleisen H, Mueller W, Pohl U, Prinz M, Benner A, Zapatka M, Gottardo NG, Driever PH, Kramm CM, Muller HL, Rutkowski S, von Hoff K, Fruhwald MC, Gnekow A, Fleischhack G, Tippelt S, Calaminus G, Monoranu CM, Perry A, Jones C, Jacques TS, Radlwimmer B, Gessi M, Pietsch T, Schramm J, Schackert G, Westphal M, Reifenberger G, Wesseling P, Weller M, Collins VP, Blumcke I, Bendszus M, Debus J, Huang A, Jabado N, Northcott PA, Paulus W, Gajjar A, Robinson GW, Taylor MD, Jaunmuktane Z, Ryzhova M, Platten M, Unterberg A, Wick W, Karajannis MA, Mittelbronn M, Acker T, Hartmann C, Aldape K, Schuller U, Buslei R, Lichter P, Kool M, Herold-Mende C, Ellison DW, Hasselblatt M, Snuderl M, Brandner S, Korshunov A, von Deimling A, Pfister SM (2018) DNA methylation-based classification of central nervous system tumours. Nature 555:469-474. https://doi.org/10.1038/nature26000

5. Castelo-Branco P, Choufani S, Mack S, Gallagher D, Zhang C, Lipman T, Zhukova N, Walker EJ, Martin D, Merino D, Wasserman JD, Elizabeth C, Alon N, Zhang L, Hovestadt V, Kool M, Jones DTW, Zadeh G, Croul S, Hawkins C, Hitzler J, Wang JCY, Baruchel S, Dirks PB, Malkin D, Pfister S, Taylor MD, Weksberg R, Tabori U (2013) Methylation of the TERT promoter and risk stratification of childhood brain tumours: an integrative genomic and molecular study. The Lancet Oncology 14:534-542. https://doi.org/10.1016/ s1470-2045(13)70110-4

6. Cavalli FMG, Hubner JM, Sharma T, Luu B, Sill M, Zapotocky M, Mack SC, Witt H, Lin T, Shih DJH, Ho B, Santi M, Emery L, Hukin J, Dunham C, McLendon RE, Lipp ES, Gururangan S, Grossbach A, French P, Kros JM, van Veelen MC, Rao AAN, Giannini C, Leary S, Jung S, Faria CC, Mora J, Schuller U, Alonso MM, Chan JA, Klekner A, Chambless LB, Hwang El, Massimino M, Eberhart CG, Karajannis MA, Lu B, Liau LM, Zollo M, Ferrucci V, Carlotti C, Tirapelli DPC, Tabori U, Bouffet E, Ryzhova M, Ellison DW, Merchant TE, Gilbert MR, Armstrong TS, Korshunov A, Pfister SM, Taylor MD, Aldape K, Pajtler KW, Kool M, Ramaswamy V (2018) Heterogeneity within the PF-EPN-B ependymoma subgroup. Acta Neuropathol 136:227-237. https://doi.org/10. 1007/s00401-018-1888-x

7. Ellison DW, Kocak M, Figarella-Branger D, Felice G, Catherine G, Pietsch T, Frappaz D, Massimino M, Grill J, Boyett JM, Grundy RG (2011) Histopathological grading of pediatric ependymoma: reproducibility and clinical relevance in European trial cohorts. J Negat Results Biomed 10:7. https://doi.org/10.1186/1477-5751-10-7 
8. Ellison DW, McLendon R, Wiestler OD, Kros JM, Korshunov A, Ng H-K, Witt H, Hirose T (2016) Ependymoma. In: OH LDN, Wiestler OD, Cavenee WK, Ellison DW, Figarella-Branger D, Perry A, Reifenberger G, von Deimling A (eds) WHO classification of Tumours of the central nervous system (revised 4th edition). International Agency for Research on Cancer, Lyon, pp 106-111

9. Figarella-Branger D, Lechapt-Zalcman E, Tabouret E, Junger S, de Paula AM, Bouvier C, Colin C, Jouvet A, Forest F, Andreiuolo F, Quintin-Roue I, Machet MC, Heitzmann A, Milin S, Sevestre H, Godfraind C, Labrousse F, Metellus P, Scavarda D, Pietsch T (2016) Supratentorial clear cell ependymomas with branching capillaries demonstrate characteristic clinicopathological features and pathological activation of nuclear factor-kappaB signaling. Neuro-Oncology 18:919-927. https://doi.org/10.1093/neuonc/now025

10. Gojo JLD, Spiegl-Kreinecker S, Pajtler KW, Neumayer K, Korbel P, Araki A, Brandstetter A, Mohr T, Hovestadt V, Chavez L, Kirchhofer D, Ricken G, Stefanits H, Korshunov A, Pfister SM, Dieckmann K, Azizi AA, Czech T, Filipits M, Kool M, Peyrl A, Slavc I, Berger W, Haberler C (2017) Telomerase activation in posterior fossa group a ependymomas is associated with dismal prognosis and chromosome 1q gain. Neuro-Oncology 19:1183-1194. https://doi.org/10.1093/neuonc/nox027|

11. Gururangan S, Fangusaro J, Young Poussaint T, Onar-Thomas A, Gilbertson RJ, Vajapeyam S, Gajjar A, Goldman S, Friedman HS, Packer RJ, Boyett JM, Kun LE, McLendon R (2012) Lack of efficacy of bevacizumab + irinotecan in cases of pediatric recurrent ependymoma--a pediatric brain tumor consortium study. Neuro-Oncology 14:1404-1412. https://doi.org/10.1093/ neuonc/nos213

12. Kao YC, Sung YS, Zhang L, Chen CL, Huang SC, Antonescu CR (2017) Expanding the molecular signature of ossifying fibromyxoid tumors with two novel gene fusions: CREBBP-BCORL1 and KDM2A-WWTR1. Genes Chromosomes Cancer 56:42-50. https://doi.org/10.1002/gcc.22400

13. Kilday JP, Mitra B, Domerg C, Ward J, Andreiuolo F, Osteso-lbanez T, Mauguen A, Varlet P, Le Deley MC, Lowe J, Ellison DW, Gilbertson RJ, Coyle B, Grill J, Grundy RG (2012) Copy number gain of 1q25 predicts poor progression-free survival for pediatric intracranial ependymomas and enables patient risk stratification: a prospective European clinical trial cohort analysis on behalf of the Children's Cancer Leukaemia group (CCLG), Societe Francaise d'Oncologie Pediatrique (SFOP), and International Society for Pediatric Oncology (SIOP). Clin Cancer Res 18:2001-2011. https://doi.org/ 10.1158/1078-0432.CCR-11-2489

14. Kim D, Salzberg SL (2011) TopHat-fusion: an algorithm for discovery of novel fusion transcripts. Genome Biol 12:R72. https://doi.org/10.1186/gb2011-12-8-r72

15. Kim JG, Takeshima H, Niwa T, Rehnberg E, Shigematsu Y, Yoda Y, Yamashita S, Kushima R, Maekita T, Ichinose M, Katai H, Park WS, Hong YS, Park CH, Ushijima T (2013) Comprehensive DNA methylation and extensive mutation analyses reveal an association between the CpG island methylator phenotype and oncogenic mutations in gastric cancers. Cancer Lett 330:33-40. https://doi. org/10.1016/j.canlet.2012.11.022

16. Korshunov A, Witt H, Hielscher T, Benner A, Remke M, Ryzhova M, Milde T, Bender S, Wittmann A, Schottler A, Kulozik AE, Witt O, von Deimling A, Lichter P, Pfister S (2010) Molecular staging of intracranial ependymoma in children and adults. J Clin Oncol 28:3182-3190. https://doi.org/10.1200/JCO. 2009.27.3359

17. Lambert SR, Witt H, Hovestadt V, Zucknick M, Kool M, Pearson DM, Korshunov A, Ryzhova M, Ichimura K, Jabado N, Fontebasso AM, Lichter P, Pfister SM, Collins VP, Jones DT (2013) Differential expression and methylation of brain developmental genes define location-specific subsets of pilocytic astrocytoma. Acta Neuropathol 126:291-301. https://doi.org/10. 1007/s00401-013-1124-7

18. Li AM, Dunham C, Tabori U, Carret AS, McNeely PD, Johnston D, LafayCousin L, Wilson B, Eisenstat DD, Jabado N, Zelcer S, Silva M, Scheinemann K, Fryer C, Hendson G, Fotovati A, Hawkins C, Yip S, Dunn SE, Hukin J (2015) $\mathrm{EZH} 2$ expression is a prognostic factor in childhood intracranial ependymoma: a Canadian pediatric brain tumor consortium study. Cancer 121:1499-1507. https://doi.org/10.1002/cncr.29198

19. Mack SC, Witt H, Piro RM, Gu L, Zuyderduyn S, Stutz AM, Wang X, Gallo M, Garzia L, Zayne K, Zhang X, Ramaswamy V, Jager N, Jones DT, Sill M, Pugh TJ, Ryzhova M, Wani KM, Shih DJ, Head R, Remke M, Bailey SD, Zichner T, Faria CC, Barszczyk M, Stark S, Seker-Cin H, Hutter S, Johann P, Bender S, Hovestadt V, Tzaridis T, Dubuc AM, Northcott PA, Peacock J, Bertrand KC, Agnihotri S, Cavalli FM, Clarke I, Nethery-Brokx K, Creasy CL, Verma SK, Koster J, Wu X, Yao Y, Milde T, Sin-Chan P, Zuccaro J, Lau L, Pereira S,
Castelo-Branco P, Hirst M, Marra MA, Roberts SS, Fults D, Massimi L, Cho YJ, Van Meter T, Grajkowska W, Lach B, Kulozik AE, von Deimling A, Witt O, Scherer SW, Fan X, Muraszko KM, Kool M, Pomeroy SL, Gupta N, Phillips J, Huang A, Tabori U, Hawkins C, Malkin D, Kongkham PN, Weiss WA, Jabado N, Rutka JT, Bouffet E, Korbel JO, Lupien M, Aldape KD, Bader GD, Eils R, Lichter P, Dirks PB, Pfister SM, Korshunov A, Taylor MD (2014) Epigenomic alterations define lethal CIMP-positive ependymomas of infancy. Nature 506: 445-450. https://doi.org/10.1038/nature13108

20. Merchant TE, Jenkins JJ, Burger PC, Sanford RA, Sherwood SH, Jones-Wallace D, Heideman RL, Thompson SJ, Helton KJ, Kun LE (2002) Influence of tumor grade on time to progression after irradiation for localized ependymoma in children. Int J Radiat Oncol Biol Phys 53:52-57

21. Modena P, Buttarelli FR, Miceli R, Piccinin E, Baldi C, Antonelli M, Morra I, Lauriola L, Di Rocco C, Garre ML, Sardi I, Genitori L, Maestro R, Gandola L, Facchinetti F, Collini P, Sozzi G, Giangaspero F, Massimino M (2012) Predictors of outcome in an AIEOP series of childhood ependymomas: a multifactorial analysis. Neuro-Oncology 14:1346-1356. https://doi.org/10. 1093/neuonc/nos245

22. Okita Y, Narita Y, Miyakita Y, Ohno M, Matsushita Y, Fukushima S, Sumi M, Ichimura K, Kayama T, Shibui S (2012) IDH1/2 mutation is a prognostic marker for survival and predicts response to chemotherapy for grade II gliomas concomitantly treated with radiation therapy. Int J Oncol 41:1325-1336. https://doi.org/10.3892/ijo.2012.1564

23. Pagan JK, Arnold J, Hanchard KJ, Kumar R, Bruno T, Jones MJ, Richard DJ, Forrest A, Spurdle A, Verdin E, Crossley M, Fanciulli M, Chenevix-Trench G, Young DB, Khanna KK (2007) A novel corepressor, BCoR-L1, represses transcription through an interaction with CtBP. J Biol Chem 282:15248-15257. https://doi.org/10.1074/jbc.M700246200

24. Pajtler KW, Wen J, Sill M, Lin T, Orisme W, Tang B, Hubner JM, Ramaswamy V, Jia S, Dalton JD, Haupfear K, Rogers HA, Punchihewa C, Lee R, Easton J, Wu G, Ritzmann TA, Chapman R, Chavez L, Boop FA, Klimo P, Sabin ND, Ogg R, Mack SC, Freibaum BD, Kim HJ, Witt H, Jones DTW, Vo B, Gajjar A, Pounds S, Onar-Thomas A, Roussel MF, Zhang J, Taylor JP, Merchant TE, Grundy R, Tatevossian RG, Taylor MD, Pfister SM, Korshunov A, Kool M, Ellison DW (2018) Molecular heterogeneity and CXorf67 alterations in posterior fossa group a (PFA) ependymomas. Acta Neuropathol 136:211-226. https://doi. org/10.1007/s00401-018-1877-0

25. Pajtler KW, Witt H, Sill M, Jones DT, Hovestadt V, Kratochwil F, Wani K, Tatevossian R, Punchihewa C, Johann P, Reimand J, Warnatz HJ, Ryzhova M, Mack S, Ramaswamy V, Capper D, Schweizer L, Sieber L, Wittmann A, Huang $Z$, van Sluis P, Volckmann R, Koster J, Versteeg R, Fults D, Toledano H, Avigad S, Hoffman LM, Donson AM, Foreman N, Hewer E, Zitterbart K, Gilbert M, Armstrong TS, Gupta N, Allen JC, Karajannis MA, Zagzag D, Hasselblatt M, Kulozik AE, Witt O, Collins VP, von Hoff K, Rutkowski S, Pietsch T, Bader G, Yaspo ML, von Deimling A, Lichter P, Taylor MD, Gilbertson R, Ellison DW, Aldape K, Korshunov A, Kool M, Pfister SM (2015) Molecular classification of ependymal tumors across all CNS compartments, histopathological grades, and age groups. Cancer Cell 27:728-743. https:// doi.org/10.1016/j.ccell.2015.04.002

26. Panwalkar P, Clark J, Ramaswamy V, Hawes D, Yang F, Dunham C, Yip S, Hukin J, Sun Y, Schipper MJ, Chavez L, Margol A, Pekmezci M, Chung C, Banda A, Bayliss JM, Curry SJ, Santi M, Rodriguez FJ, Snuderl M, Karajannis MA, Saratsis AM, Horbinski CM, Carret AS, Wilson B, Johnston D, LafayCousin L, Zelcer S, Eisenstat D, Silva M, Scheinemann K, Jabado N, McNeely PD, Kool M, Pfister SM, Taylor MD, Hawkins C, Korshunov A, Judkins AR, Venneti S (2017) Immunohistochemical analysis of H3K27me3 demonstrates global reduction in group-a childhood posterior fossa ependymoma and is a powerful predictor of outcome. Acta Neuropathol 134:705-714. https:// doi.org/10.1007/s00401-017-1752-4

27. Parker M, Mohankumar KM, Punchihewa C, Weinlich R, Dalton JD, Li Y, Lee R, Tatevossian RG, Phoenix TN, Thiruvenkatam R, White E, Tang B, Orisme W, Gupta K, Rusch M, Chen X, Nagahawhatte P, Hedlund E, Finkelstein D, Wu G, Shurtleff S, Easton J, Boggs K, Yergeau D, Vadodaria B, Mulder HL, Becksfort J, Gupta P, Huether R, Ma J, Song G, Gajjar A, Merchant T, Boop F, Smith AA, Ding L, Lu C, Ochoa K, Zhao D, Fulton RS, Fulton LL, Mardis ER, Wilson RK, Downing JR, Green DR, Zhang J, Ellison DW, Gilbertson RJ (2014) C11 orf95-RELA fusions drive oncogenic NF-kappaB signalling in ependymoma. Nature 506:451-455. https://doi.org/10.1038/nature13109

28. Raghunathan A, Wani K, Armstrong TS, Vera-Bolanos E, Fouladi M, Gilbertson R, Gajjar A, Goldman S, Lehman NL, Metellus P, Mikkelsen T, Necesito-Reyes MJ, Omuro A, Packer RJ, Partap S, Pollack IF, Prados MD, 
Robins HI, Soffietti R, Wu J, Miller CR, Gilbert MR, Aldape KD (2013) Histological predictors of outcome in ependymoma are dependent on anatomic site within the central nervous system. Brain Pathol 23:584-594. https://doi.org/10.1111/bpa.12050

29. Ramaswamy V, Hielscher T, Mack SC, Lassaletta A, Lin T, Pajtler KW, Jones DTW, Luu B, Cavalli FMG, Aldape K, Remke M, Mynarek M, Rutkowski S, Gururangan S, McLendon RE, Lipp ES, Dunham C, Hukin J, Eisenstat DD, Fulton D, van Landeghem FKH, Santi M, van Veelen MLC, Van Meir EG, Osuka S, Fan X, Muraszko KM, Tirapelli DPC, Oba-Shinjo SM, Marie SKN, Carlotti CG, Lee JY, Nageswara Rao AA, Giannini C, Faria CC, Nunes S, Mora J, Hamilton RL, Hauser P, Jabado N, Petrecca K, Jung S, Massimi L, Zollo M, Cinalli G, Bognar L, Klekner A, Hortobagyi T, Leary S, Ermoian RP, Olson JM, Leonard JR, Gardner C, Grajkowska WA, Chambless LB, Cain J, Eberhart CG, Ahsan S, Massimino M, Giangaspero F, Buttarelli FR, Packer RJ, Emery L, Yong WH, Soto H, Liau LM, Everson R, Grossbach A, Shalaby T, Grotzer M, Karajannis MA, Zagzag D, Wheeler $H$, von Hoff K, Alonso MM, Tunon T, Schuller U, Zitterbart K, Sterba J, Chan JA, Guzman M, Elbabaa SK, Colman H, Dhall G, Fisher PG, Fouladi M, Gajjar A, Goldman S, Hwang E, Kool M, Ladha H, Vera-Bolanos E, Wani K, Lieberman F, Mikkelsen T, Omuro AM, Pollack IF, Prados M, Robins HI, Soffietti R, Wu J, Metellus P, Tabori U, Bartels U, Bouffet E, Hawkins CE, Rutka JT, Dirks P, Pfister SM, Merchant TE, Gilbert MR, Armstrong TS, Korshunov A, Ellison DW, Taylor MD (2016) Therapeutic impact of Cytoreductive surgery and irradiation of posterior Fossa Ependymoma in the molecular era: a retrospective multicohort analysis. J Clin Oncol 34:2468-2477. https://doi.org/10.1200/jco.2015.65.7825

30. Sturm D, Orr BA, Toprak UH, Hovestadt V, Jones DT, Capper D, Sill M, Buchhalter I, Northcott PA, Leis I, Ryzhova M, Koelsche C, Pfaff E, Allen SJ, Balasubramanian G, Worst BC, Pajtler KW, Brabetz S, Johann PD, Sahm F, Reimand J, Mackay A, Carvalho DM, Remke M, Phillips JJ, Perry A, Cowdrey C, Drissi R, Fouladi M, Giangaspero F, Lastowska M, Grajkowska W, Scheurlen W, Pietsch T, Hagel C, Gojo J, Lotsch D, Berger W, Slavc I, Haberler C, Jouvet A, Holm S, Hofer S, Prinz M, Keohane C, Fried I, Mawrin C, Scheie D, Mobley BC, Schniederjan MJ, Santi M, Buccoliero AM, Dahiya S, Kramm CM, von Bueren AO, von Hoff K, Rutkowski S, Herold-Mende C, Fruhwald MC, Milde T, Hasselblatt M, Wesseling P, Rossler J, Schuller U, Ebinger M, Schittenhelm J, Frank S, Grobholz R, Vajtai I, Hans V, Schneppenheim R, Zitterbart K, Collins VP, Aronica E, Varlet P, Puget S, Dufour C, Grill J, Figarella-Branger D, Wolter M, Schuhmann MU, Shalaby T, Grotzer M, van Meter T, Monoranu CM, Felsberg J, Reifenberger G, Snuderl M, Forrester LA, Koster J, Versteeg R, Volckmann R, van Sluis P, Wolf S, Mikkelsen T, Gajjar A, Aldape K, Moore AS, Taylor MD, Jones C, Jabado N, Karajannis MA, Eils R, Schlesner M, Lichter P, von Deimling A, Pfister SM, Ellison DW, Korshunov A, Kool M (2016) New brain tumor entities emerge from molecular classification of CNS-PNETs. Cell 164:1060-1072. https://doi.org/10.1016/j.cell.2016.01.015

31. Tabori U, Ma J, Carter M, Zielenska M, Rutka J, Bouffet E, Bartels U, Malkin D, Hawkins C (2006) Human telomere reverse transcriptase expression predicts progression and survival in pediatric intracranial ependymoma. J Clin Oncol 24:1522-1528. https://doi.org/10.1200/JCO.2005.04.2127

32. Tihan T, Zhou T, Holmes E, Burger PC, Ozuysal S, Rushing EJ (2008) The prognostic value of histological grading of posterior fossa ependymomas in children: a Children's oncology group study and a review of prognostic factors. Mod Pathol 21:165-177. https://doi.org/10.1038/modpathol.3800999

33. Turcan S, Rohle D, Goenka A, Walsh LA, Fang F, Yilmaz E, Campos C, Fabius AW, Lu C, Ward PS, Thompson CB, Kaufman A, Guryanova O, Levine R, Heguy A, Viale A, Morris LG, Huse JT, Mellinghoff IK, Chan TA (2012) IDH1 mutation is sufficient to establish the glioma hypermethylator phenotype. Nature 483:479-483. https://doi.org/10.1038/nature10866

34. Ueno-Yokohata $\mathrm{H}$, Okita H, Nakasato K, Akimoto S, Hata J, Koshinaga T, Fukuzawa M, Kiyokawa N (2015) Consistent in-frame internal tandem duplications of BCOR characterize clear cell sarcoma of the kidney. Nat Genet 47:861-863. https://doi.org/10.1038/ng.3338

35. Venkatramani R, Ji L, Lasky J, Haley K, Judkins A, Zhou S, Sposto R, Olshefski R, Garvin J, Tekautz T, Kennedy G, Rassekh SR, Moore T, Gardner S, Allen J, Shore R, Moertel C, Atlas M, Dhall G, Finlay J (2013) Outcome of infants and young children with newly diagnosed ependymoma treated on the "head start" III prospective clinical trial. J Neuro-Oncol 113:285-291. https://doi.org/10.1007/ s11060-013-1111-9

36. Wachtel M, Schafer BW (2017) PAX3-FOXO1: zooming in on an "undruggable" target. Semin Cancer Biol. https://doi.org/10.1016/.semcancer.2017.11.006

37. Witt H, Mack SC, Ryzhova M, Bender S, Sill M, Isserlin R, Benner A, Hielscher T, Milde T, Remke M, Jones DT, Northcott PA, Garzia L, Bertrand KC, Wittmann A,
Yao Y, Roberts SS, Massimi L, Van Meter T, Weiss WA, Gupta N, Grajkowska W, Lach B, Cho YJ, von Deimling A, Kulozik AE, Witt O, Bader GD, Hawkins CE, Tabori U, Guha A, Rutka JT, Lichter P, Korshunov A, Taylor MD, Pfister SM (2011) Delineation of two clinically and molecularly distinct subgroups of posterior fossa ependymoma. Cancer Cell 20:143-157. https://doi.org/10.1016/j.ccr.2011.07.007

38. Zong L, Hattori N, Yoda Y, Yamashita S, Takeshima H, Takahashi T, Maeda M, Katai H, Nanjo S, Ando T, Seto Y, Ushijima T (2015) Establishment of a DNA methylation marker to evaluate cancer cell fraction in gastric cancer. Gastric Cancer. https://doi.org/10.1007/s10120-015-0475-2

\section{Ready to submit your research? Choose BMC and benefit from:}

- fast, convenient online submission

- thorough peer review by experienced researchers in your field

- rapid publication on acceptance

- support for research data, including large and complex data types

- gold Open Access which fosters wider collaboration and increased citations

- maximum visibility for your research: over $100 \mathrm{M}$ website views per year

At BMC, research is always in progress.

Learn more biomedcentral.com/submissions 